\title{
Synthesis and Evaluation of Derrubone and Select Analogues
}

Jedidiah M. Hastings, M. Kyle Hadden, and Brian S. J. Blagg*

\section{Spectra}

Department of Medicinal Chemistry, The University of Kansas, 1251 Wescoe Hall Drive, Malott 4070, Lawrence, Kansas 66045-7563

bblagg@ku.edu 
Table of Contents

${ }^{1} \mathrm{H}-\mathrm{NMR}$ of spectrum of 1

${ }^{13} \mathrm{C}-\mathrm{NMR}$ of spectrum of 1 S5

${ }^{1} \mathrm{H}-\mathrm{NMR}$ of spectrum of 4 S6

${ }^{1} \mathrm{H}-\mathrm{NMR}$ of spectrum of 5 S7

${ }^{13} \mathrm{C}-\mathrm{NMR}$ of spectrum of 5 S8

${ }^{1} \mathrm{H}-\mathrm{NMR}$ of spectrum of 6 S9

${ }^{13} \mathrm{C}-\mathrm{NMR}$ of spectrum of 6 S10

${ }^{1} \mathrm{H}-\mathrm{NMR}$ of spectrum of 8 S11

${ }^{13} \mathrm{C}$-NMR of spectrum of 8 S12

${ }^{1} \mathrm{H}-\mathrm{NMR}$ of spectrum of 9

$\mathrm{S} 13$

${ }^{13} \mathrm{C}$-NMR of spectrum of 9

S14

${ }^{1} \mathrm{H}-\mathrm{NMR}$ of spectrum of 11

S15

${ }^{13} \mathrm{C}-\mathrm{NMR}$ of spectrum of 11

S16

${ }^{1} \mathrm{H}-\mathrm{NMR}$ of spectrum of 13

S17

${ }^{13} \mathrm{C}-\mathrm{NMR}$ of spectrum of 13

S18

${ }^{1} \mathrm{H}-\mathrm{NMR}$ of spectrum of 14

S19

${ }^{1} \mathrm{H}-\mathrm{NMR}$ of spectrum of 15

S20

${ }^{13} \mathrm{C}-\mathrm{NMR}$ of spectrum of 15

$\mathrm{S} 21$

${ }^{1} \mathrm{H}-\mathrm{NMR}$ of spectrum of 16

S22

${ }^{13} \mathrm{C}$-NMR of spectrum of 16

S23

${ }^{1} \mathrm{H}-\mathrm{NMR}$ of spectrum of $18 \mathrm{a}$

S24

${ }^{13} \mathrm{C}-\mathrm{NMR}$ of spectrum of $18 \mathrm{a}$

S25

${ }^{1} \mathrm{H}-\mathrm{NMR}$ of spectrum of $18 \mathrm{~b}$

S26

${ }^{13} \mathrm{C}-\mathrm{NMR}$ of spectrum of $18 \mathrm{~b}$

S27

${ }^{1} \mathrm{H}-\mathrm{NMR}$ of spectrum of $18 \mathrm{c}$

S28

${ }^{13} \mathrm{C}-\mathrm{NMR}$ of spectrum of $18 \mathrm{c}$

S29

${ }^{1} \mathrm{H}-\mathrm{NMR}$ of spectrum of $18 \mathrm{~d}$

S30

${ }^{13} \mathrm{C}-\mathrm{NMR}$ of spectrum of $18 \mathrm{~d}$

S31

${ }^{1} \mathrm{H}-\mathrm{NMR}$ of spectrum of $18 \mathrm{e}$

S32

${ }^{13} \mathrm{C}-\mathrm{NMR}$ of spectrum of $18 \mathrm{e}$

S33

${ }^{1} \mathrm{H}-\mathrm{NMR}$ of spectrum of $19 \mathrm{a} \quad \mathrm{S} 34$

${ }^{13}$ C-NMR of spectrum of 19a $\quad$ S35

${ }^{1} \mathrm{H}-\mathrm{NMR}$ of spectrum of $19 \mathrm{~b} \quad \mathrm{~S} 36$

${ }^{13} \mathrm{C}-\mathrm{NMR}$ of spectrum of $19 \mathrm{~b} \quad \mathrm{~S} 37$

${ }^{1} \mathrm{H}-\mathrm{NMR}$ of spectrum of $19 \mathrm{c} \quad \mathrm{S} 38$

${ }^{13} \mathrm{C}-\mathrm{NMR}$ of spectrum of $19 \mathrm{c} \quad \mathrm{S} 39$

${ }^{1} \mathrm{H}-\mathrm{NMR}$ of spectrum of 19d $\quad$ S40

${ }^{13} \mathrm{C}-\mathrm{NMR}$ of spectrum of 19d $\quad$ S41 
$\begin{array}{ll}{ }^{1} \mathrm{H}-\mathrm{NMR} \text { of spectrum of } 19 \mathrm{e} & \mathrm{S} 42 \\ { }^{13} \mathrm{C}-\mathrm{NMR} \text { of spectrum of 19e } & \mathrm{S} 43 \\ { }^{1} \mathrm{H}-\mathrm{NMR} \text { of spectrum of 20a } & \mathrm{S} 44 \\ { }^{13} \mathrm{C}-\mathrm{NMR} \text { of spectrum of 22a } & \mathrm{S} 45 \\ { }^{1} \mathrm{H}-\mathrm{NMR} \text { of spectrum of 22b } & \mathrm{S} 46 \\ { }^{13} \mathrm{C}-\mathrm{NMR} \text { of spectrum of 22b } & \mathrm{S} 47 \\ { }^{1} \mathrm{H}-\mathrm{NMR} \text { of spectrum of 22c } & \mathrm{S} 48 \\ { }^{13} \mathrm{C}-\mathrm{NMR} \text { of spectrum of 22c } & \mathrm{S} 49 \\ { }^{1} \mathrm{H}-\mathrm{NMR} \text { of spectrum of 22d } & \mathrm{S} 50 \\ { }^{13} \mathrm{C}-\mathrm{NMR} \text { of spectrum of 22d } & \mathrm{S} 51 \\ { }^{1} \mathrm{H}-\mathrm{NMR} \text { of spectrum of 22e } & \mathrm{S} 52 \\ { }^{13} \mathrm{C}-\mathrm{NMR} \text { of spectrum of 22e } & \mathrm{S} 53 \\ { }^{1} \mathrm{H}-\mathrm{NMR} \text { of spectrum of 23a } & \mathrm{S} 54 \\ { }^{13} \mathrm{C}-\mathrm{NMR} \text { of spectrum of 23a } & \mathrm{S} 55 \\ { }^{1} \mathrm{H}-\mathrm{NMR} \text { of spectrum of 23b } & \mathrm{S} 56 \\ { }^{13} \mathrm{C}-\mathrm{NMR} \text { of spectrum of 23b } & \mathrm{S} 57\end{array}$ 

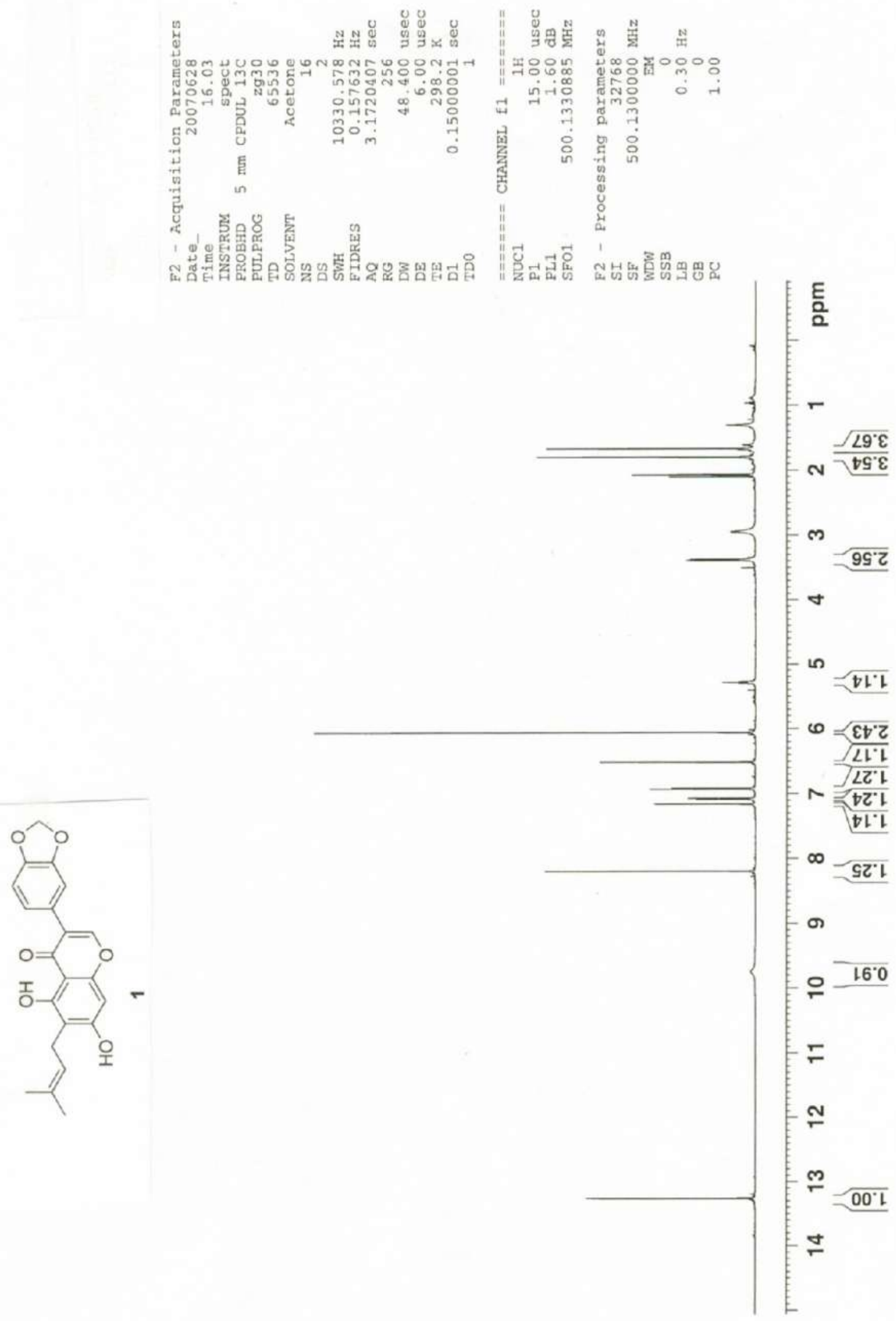


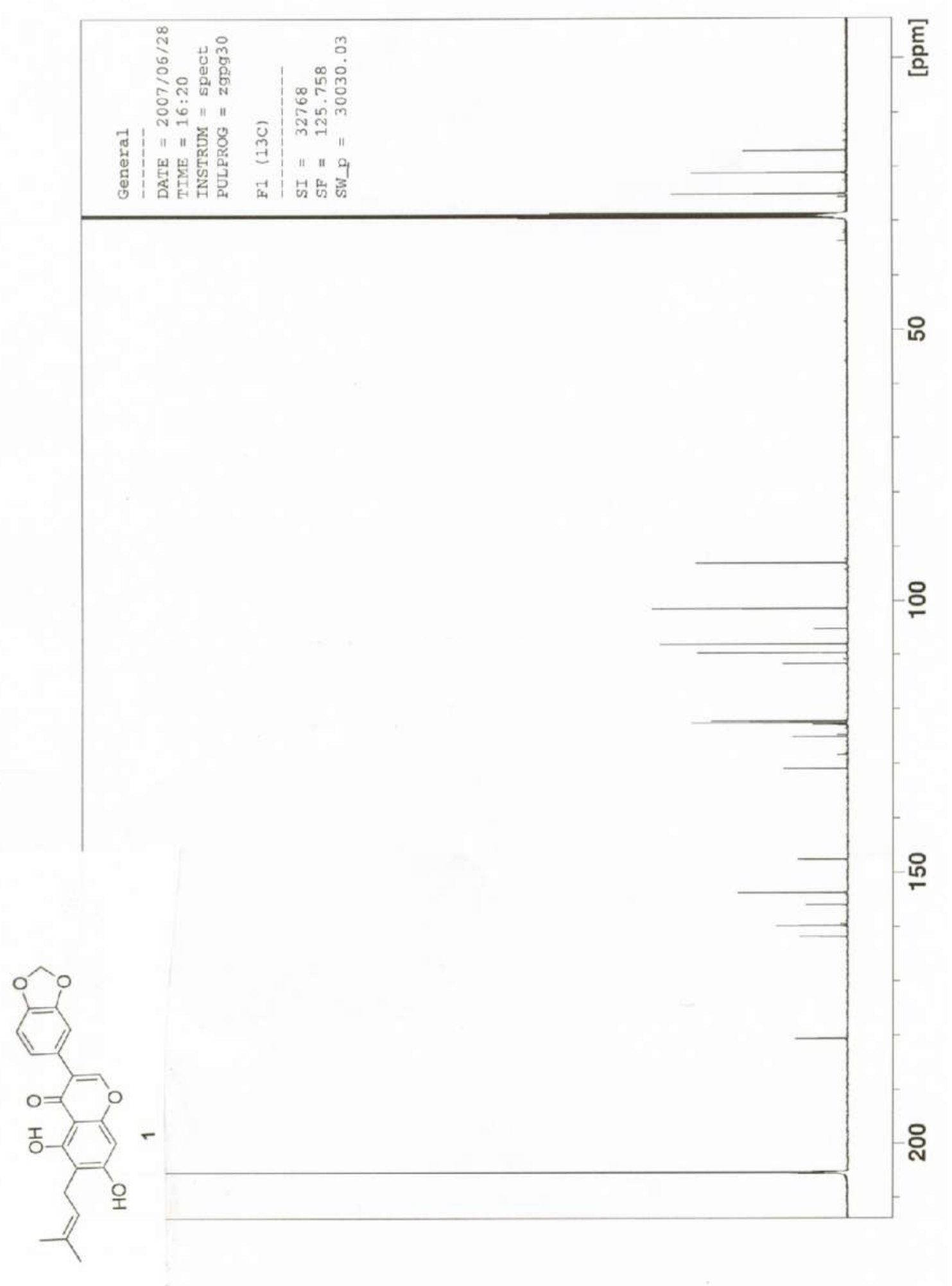



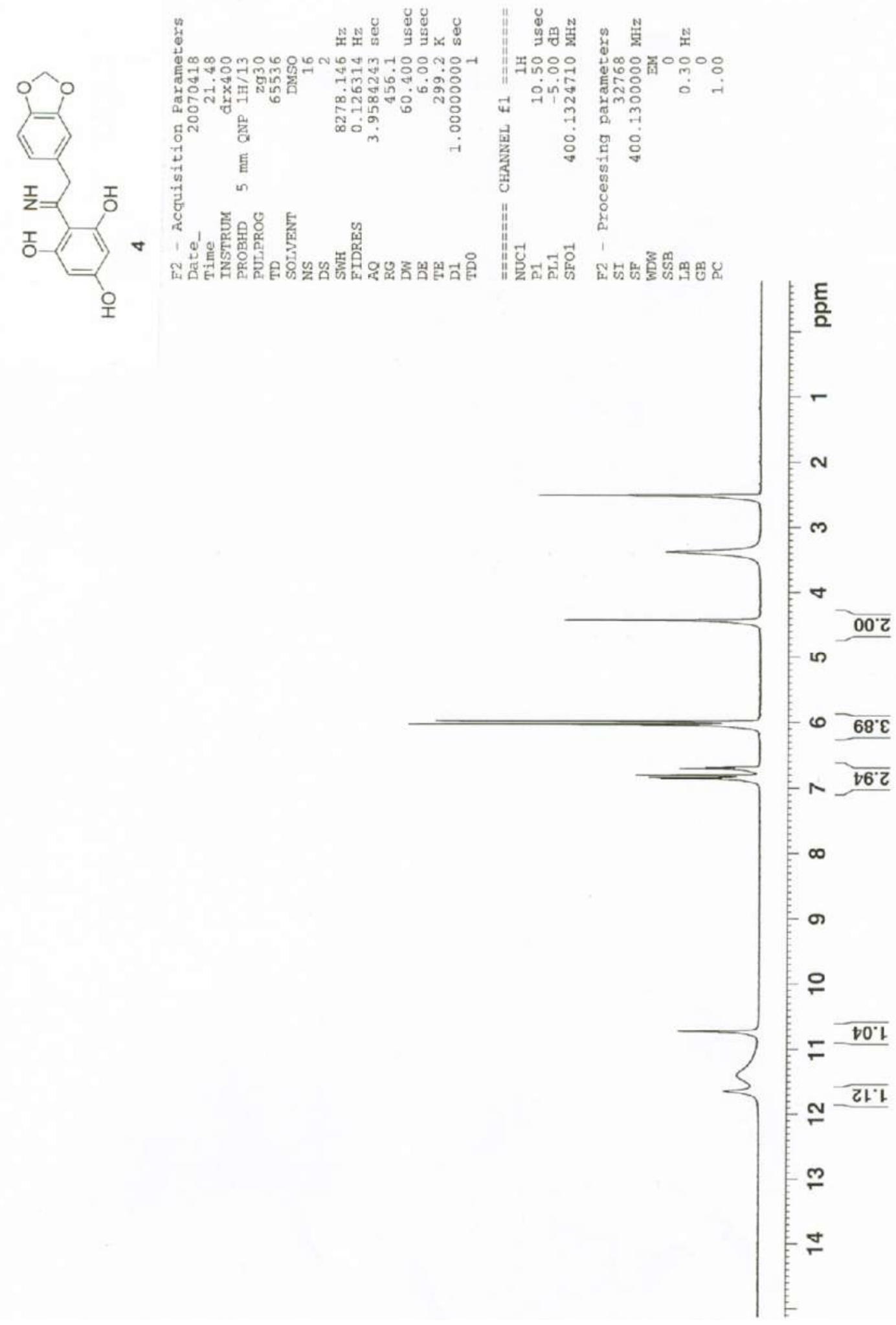

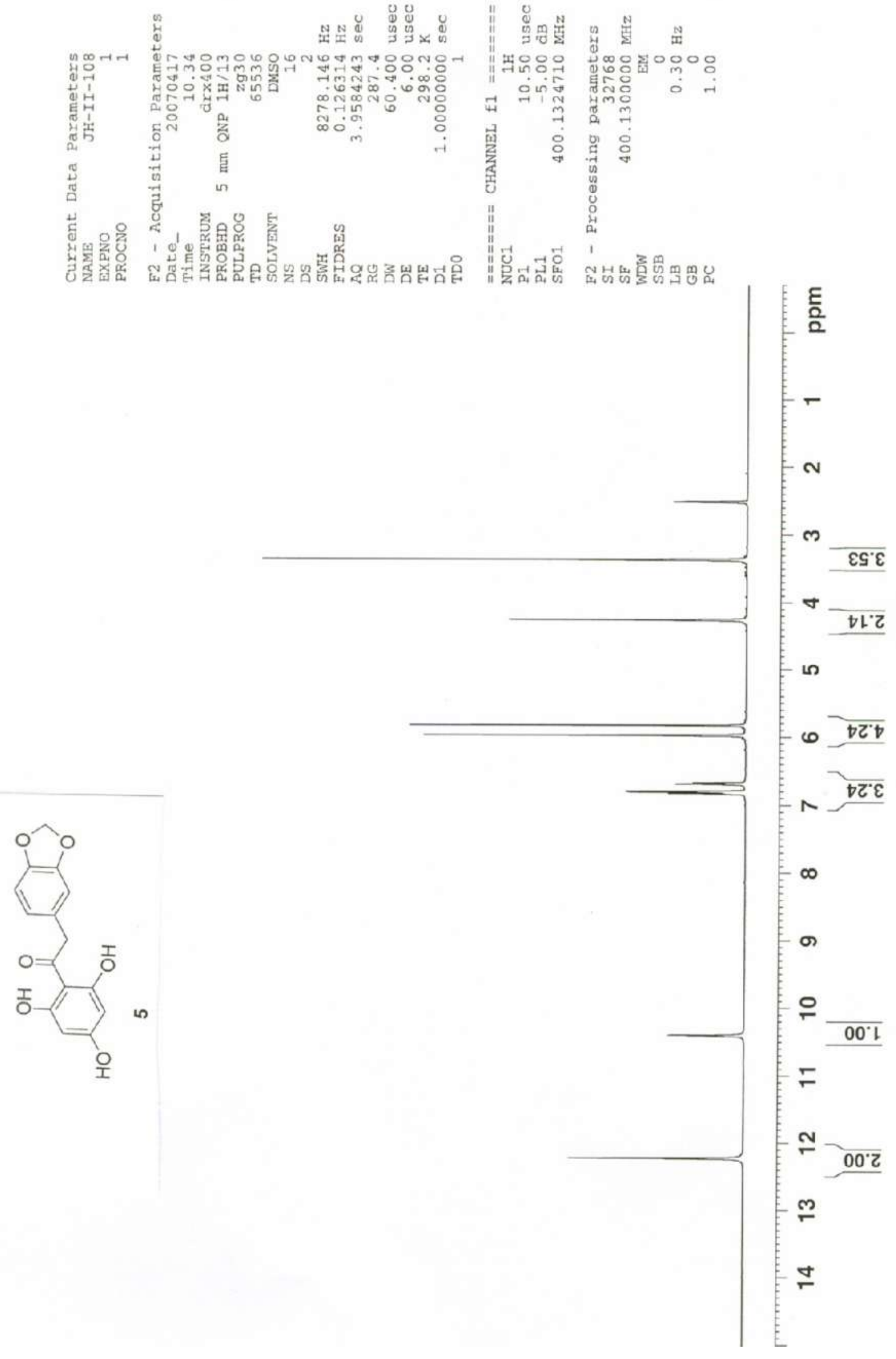

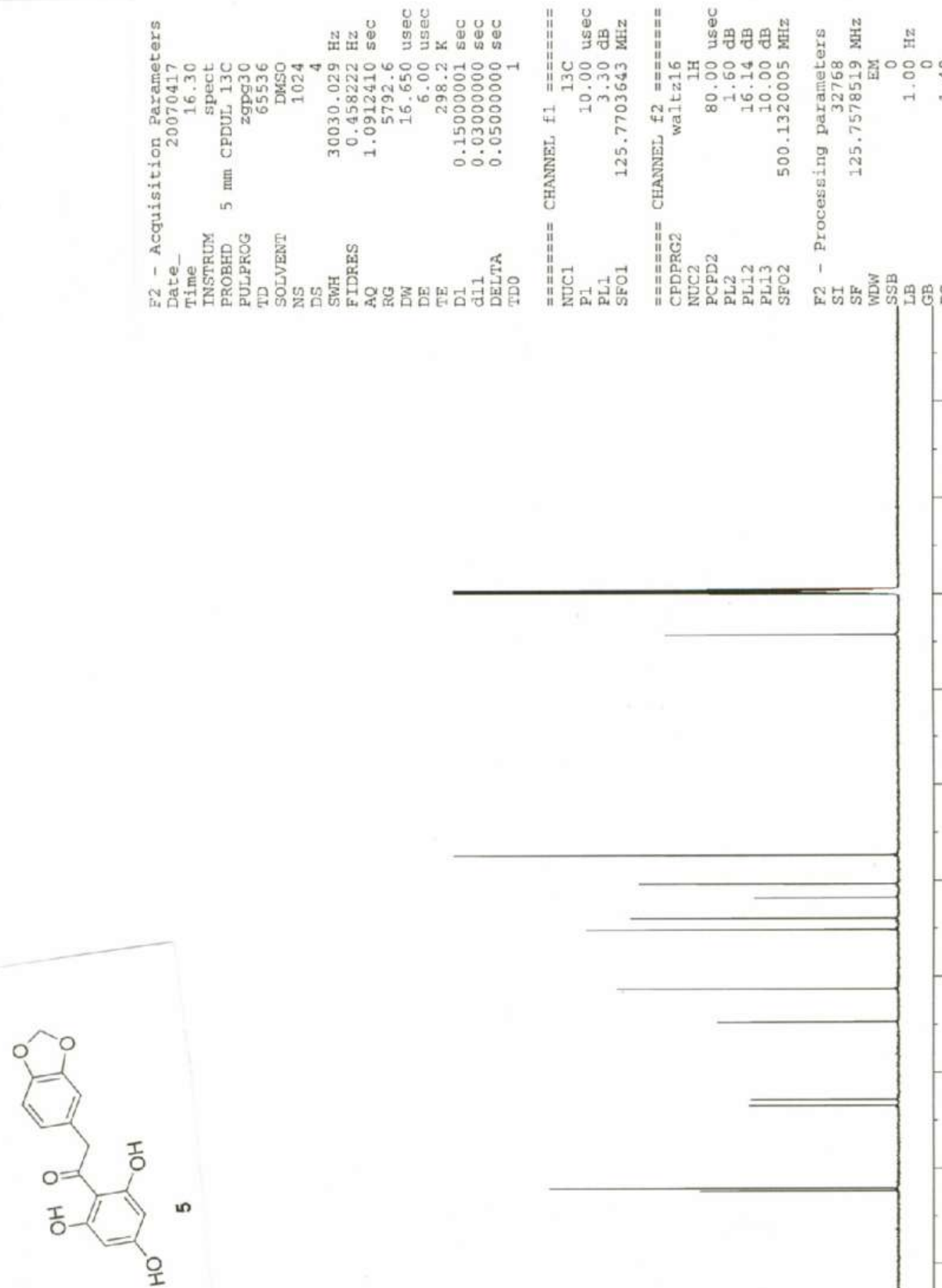
NoOmow न 4.

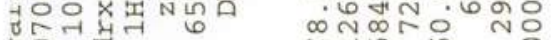

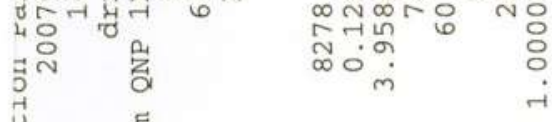

息

เก

吾

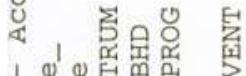

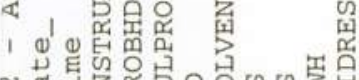

ง

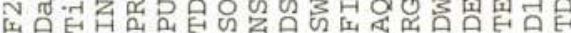

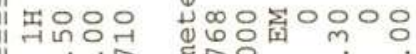

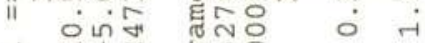

$\rightarrow$ I

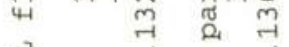

舅

:

范 유

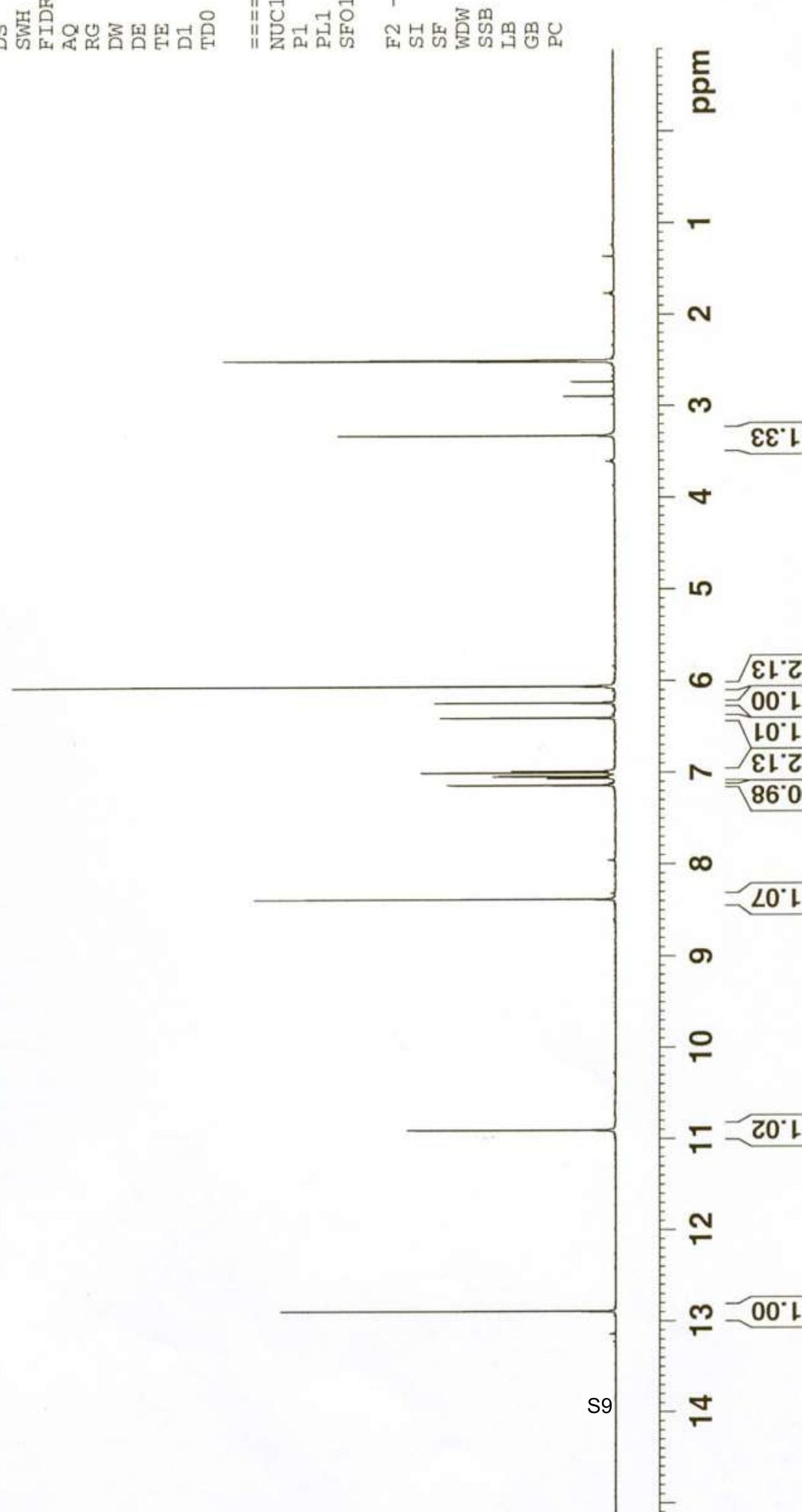



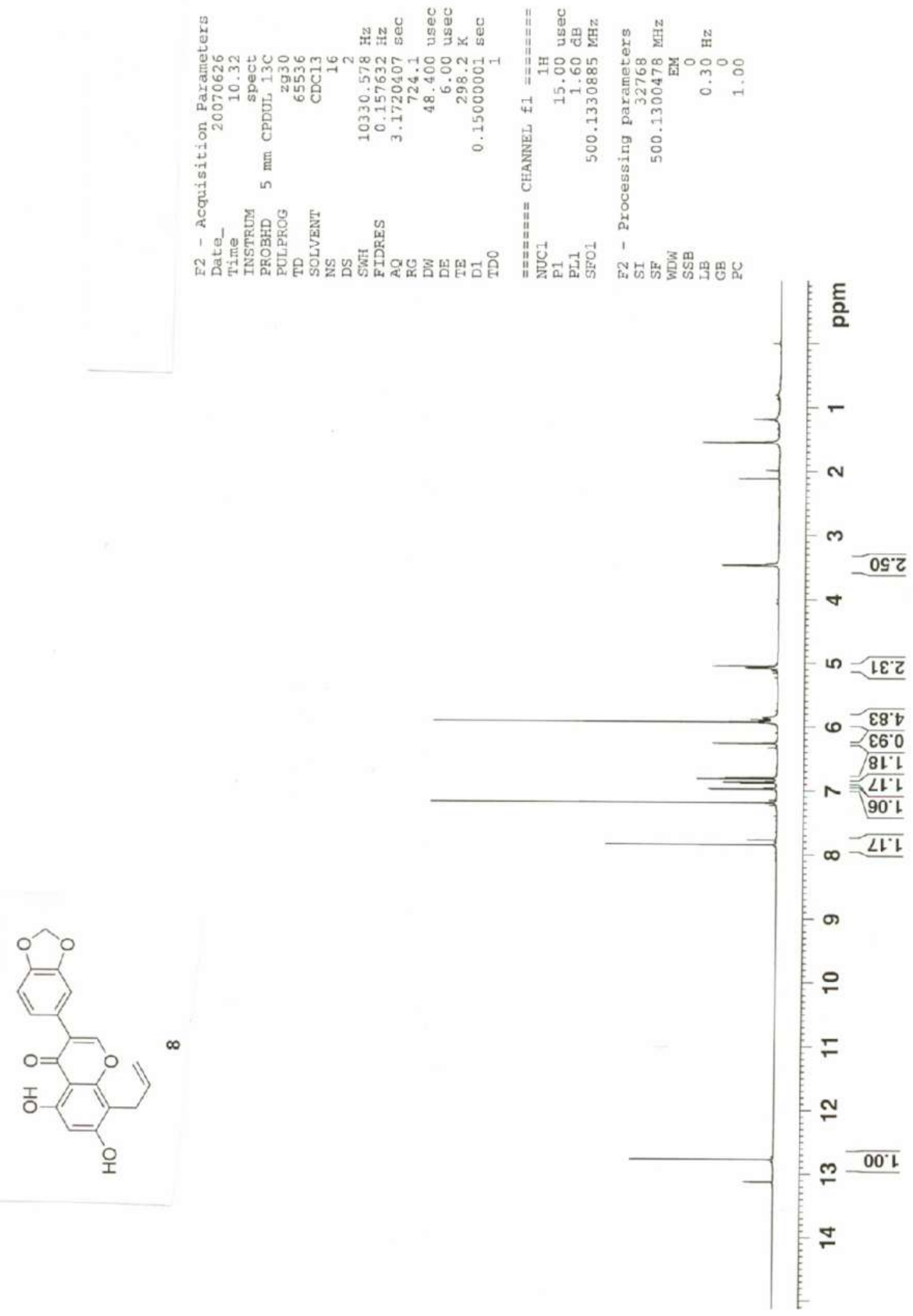


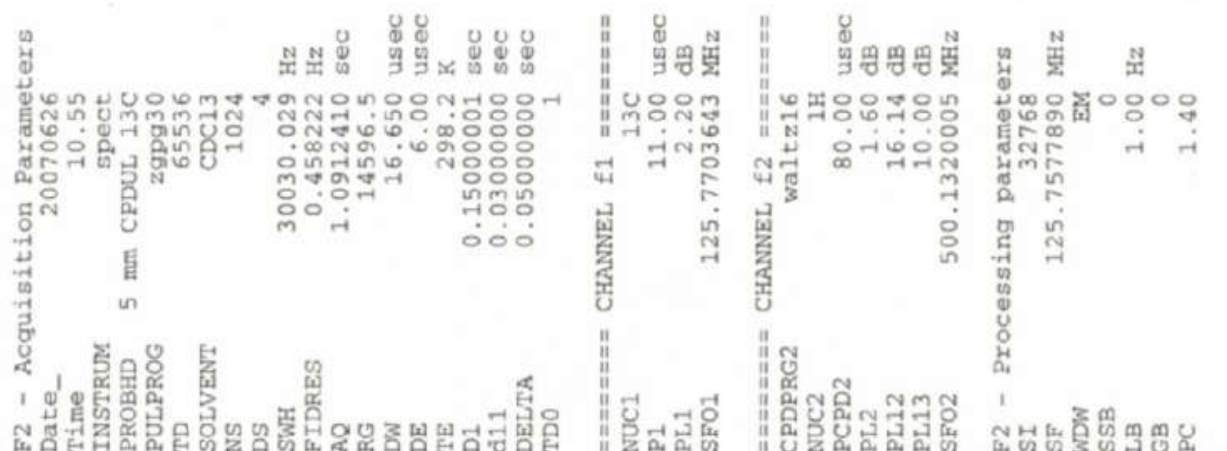

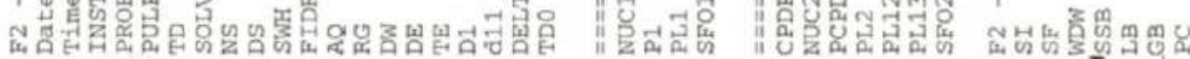

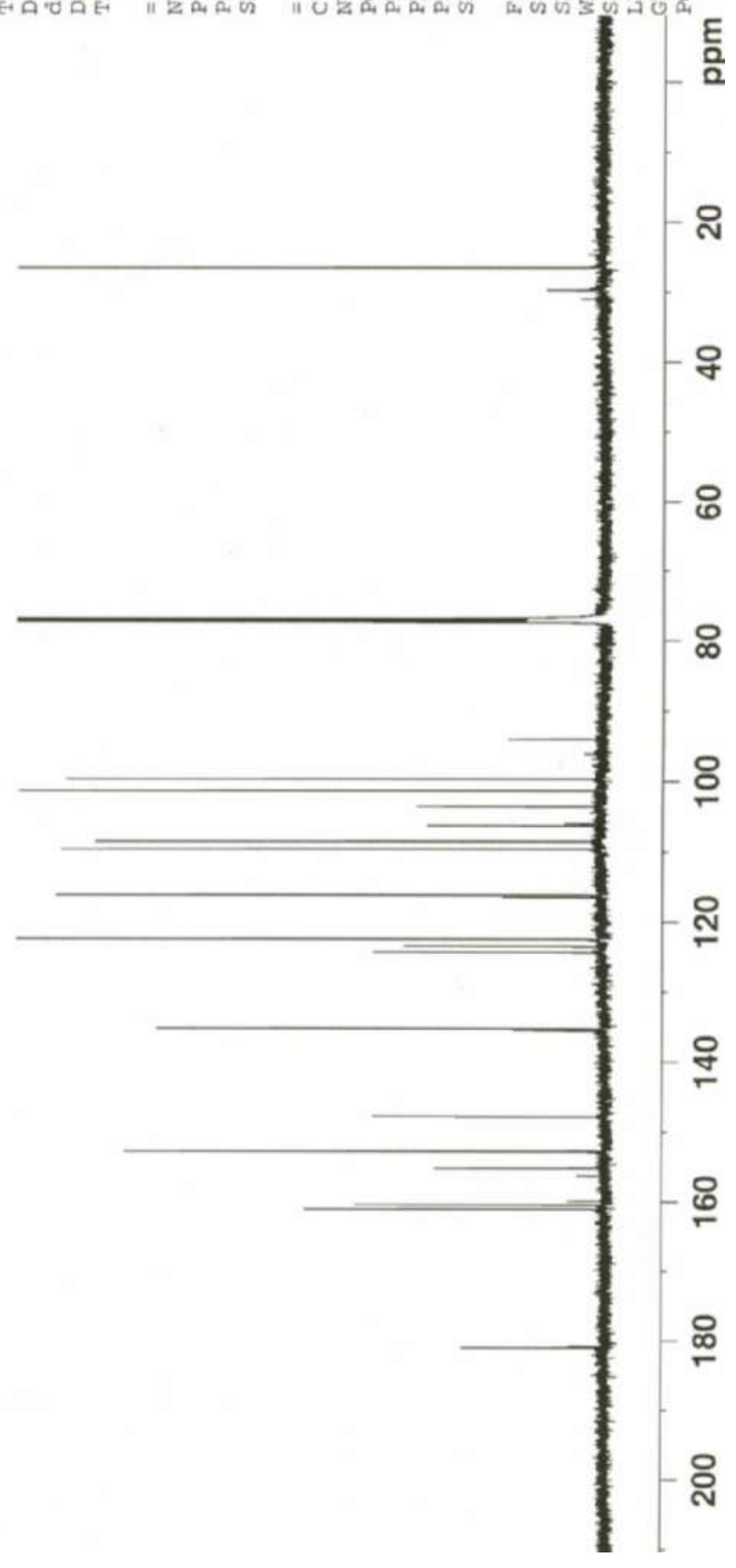




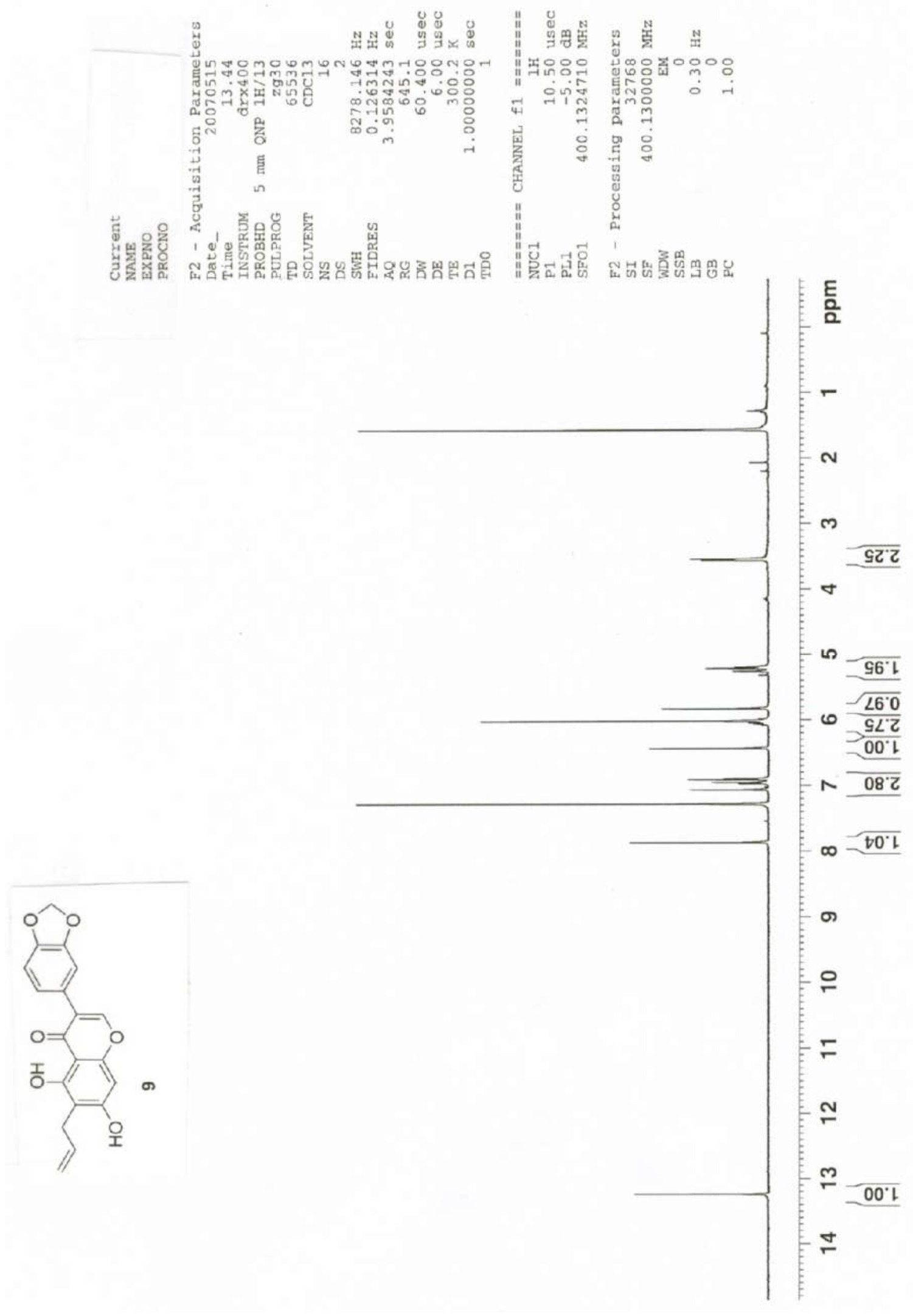




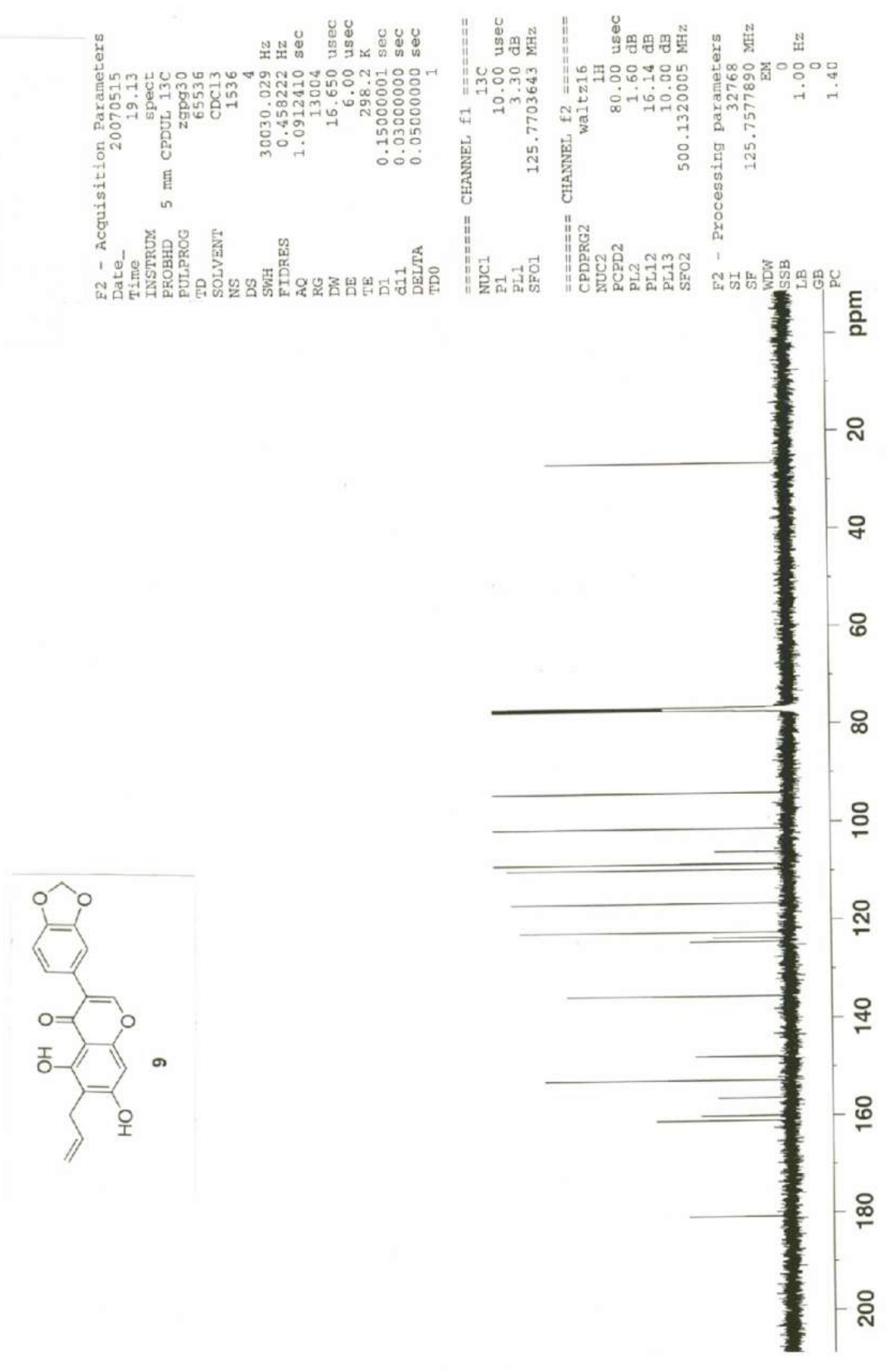




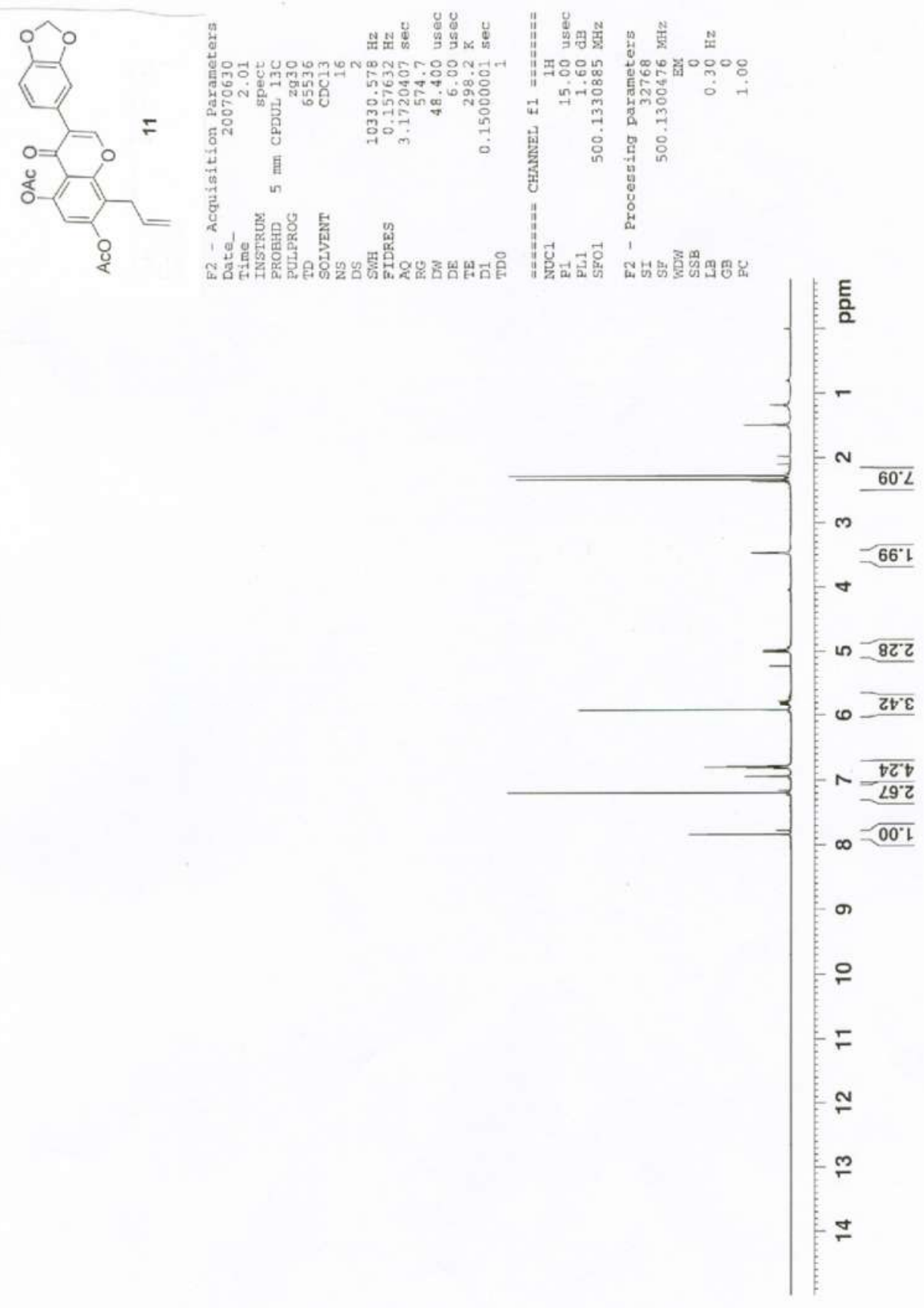




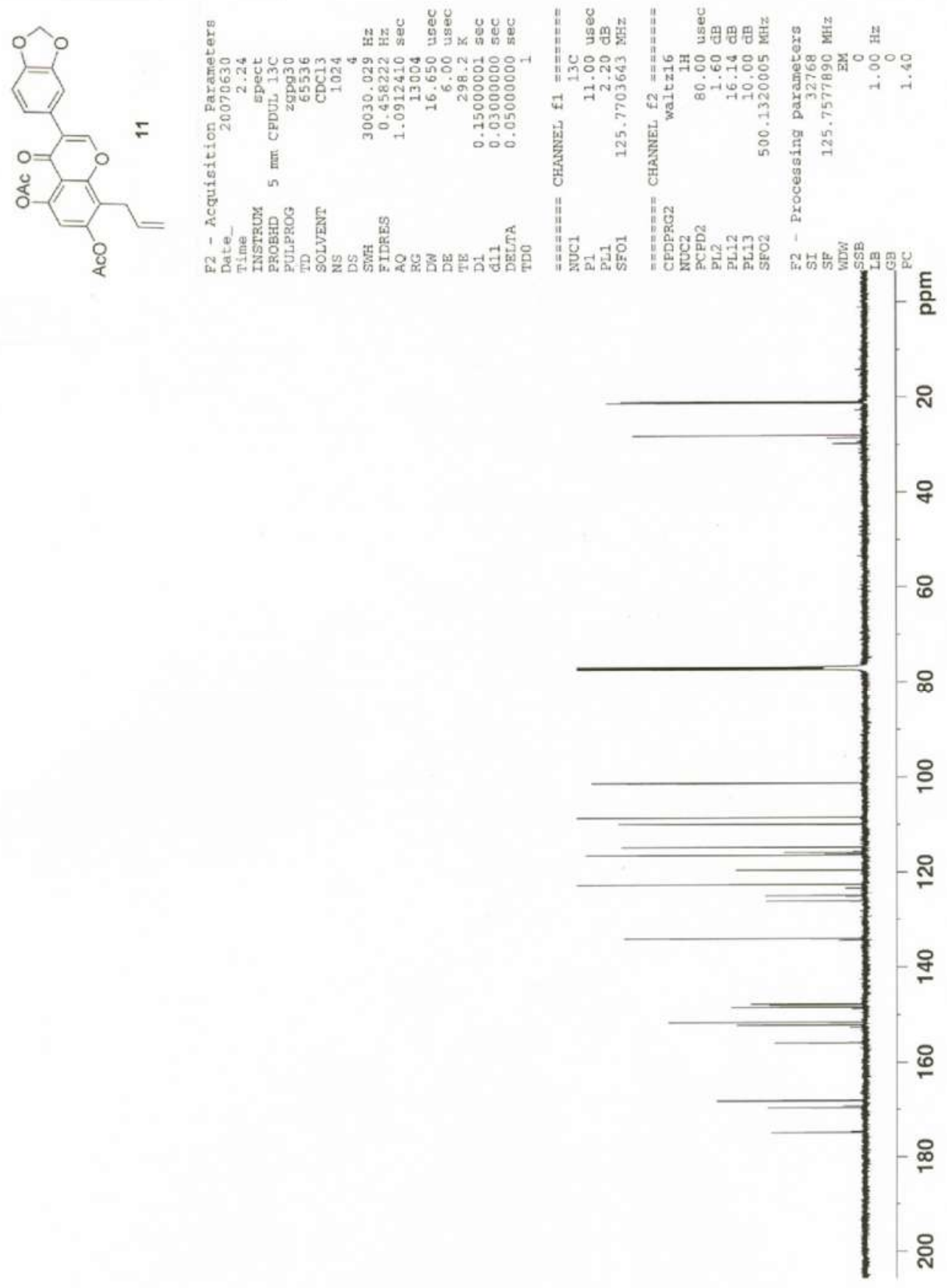




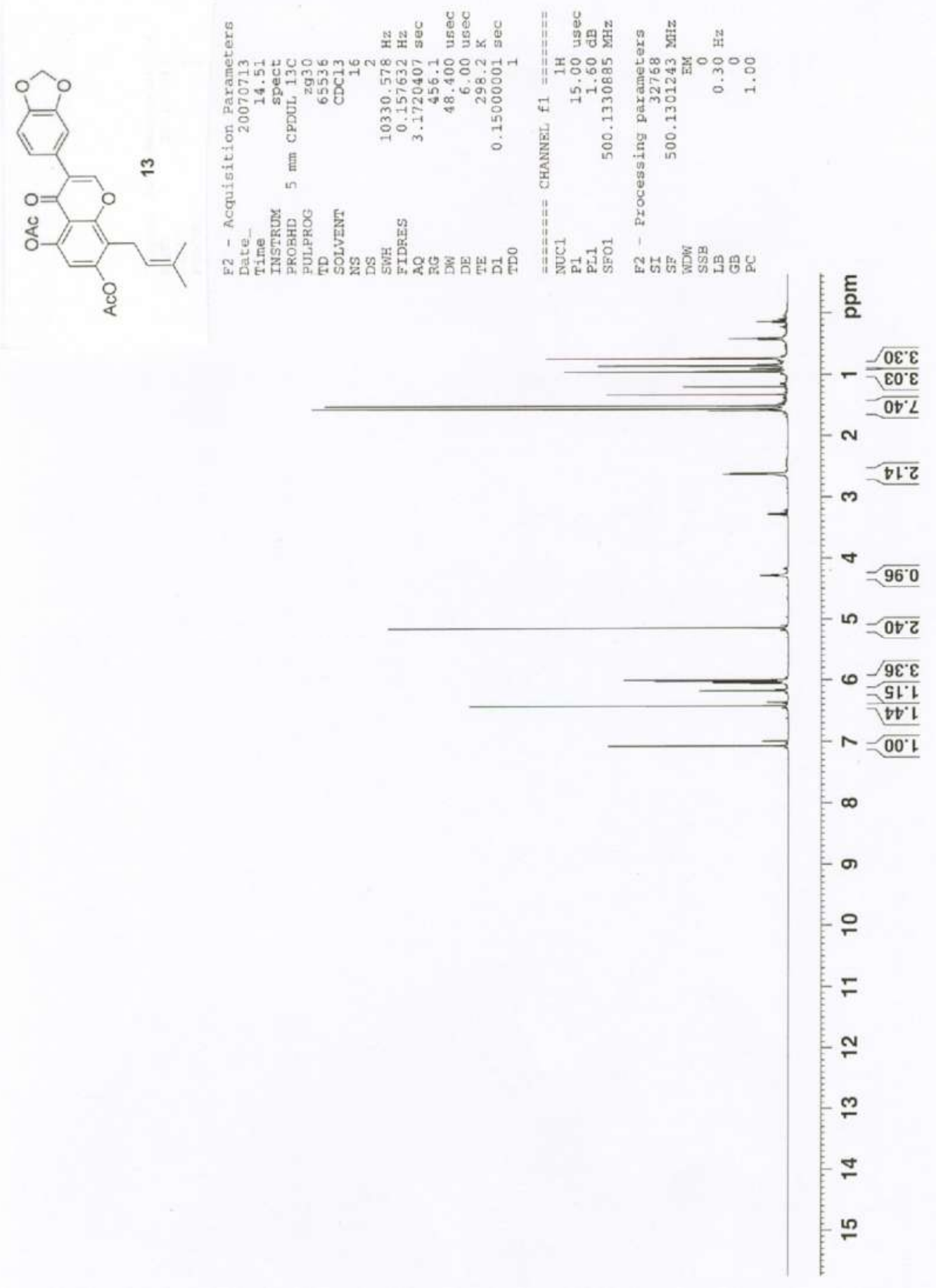



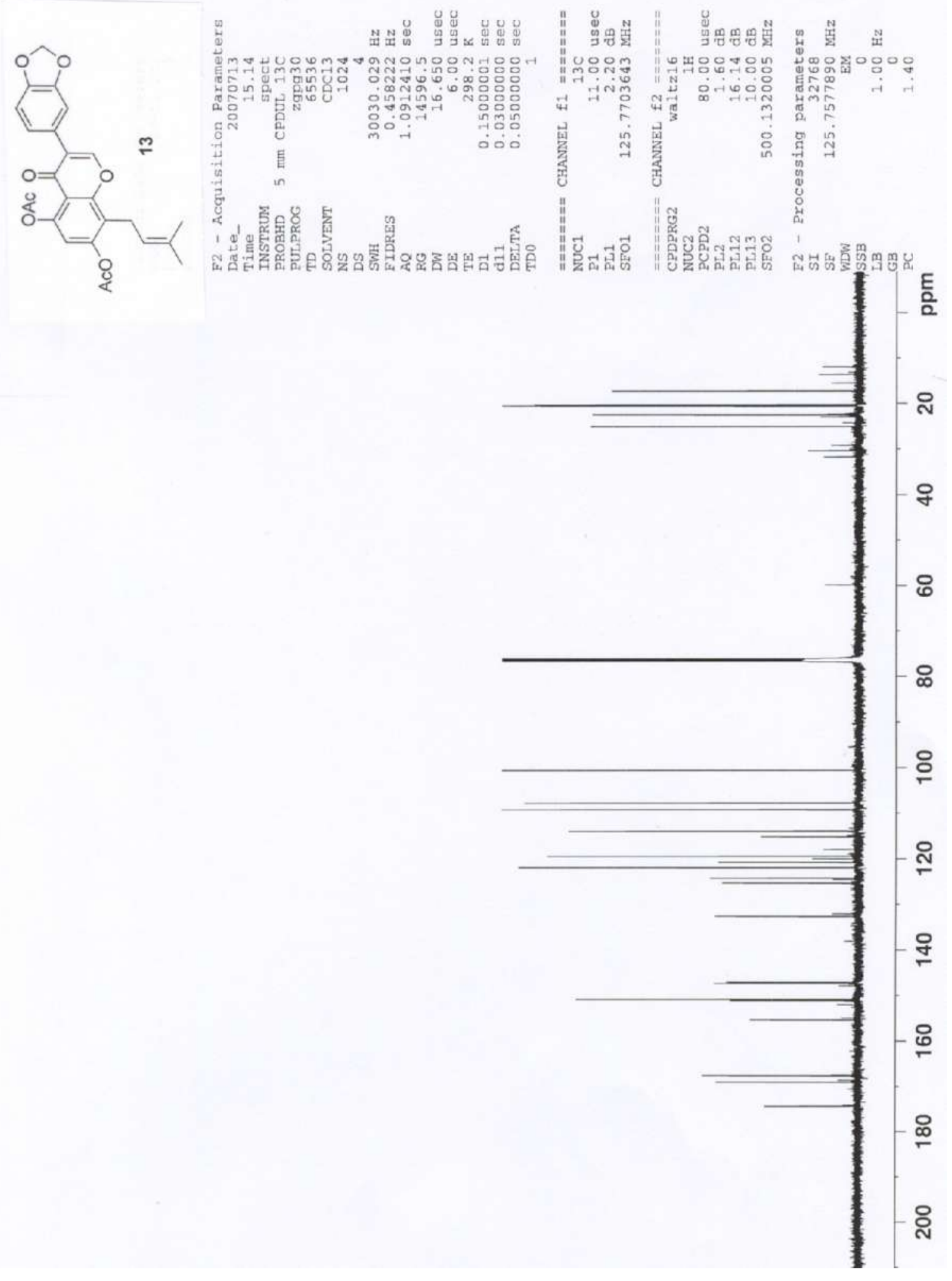

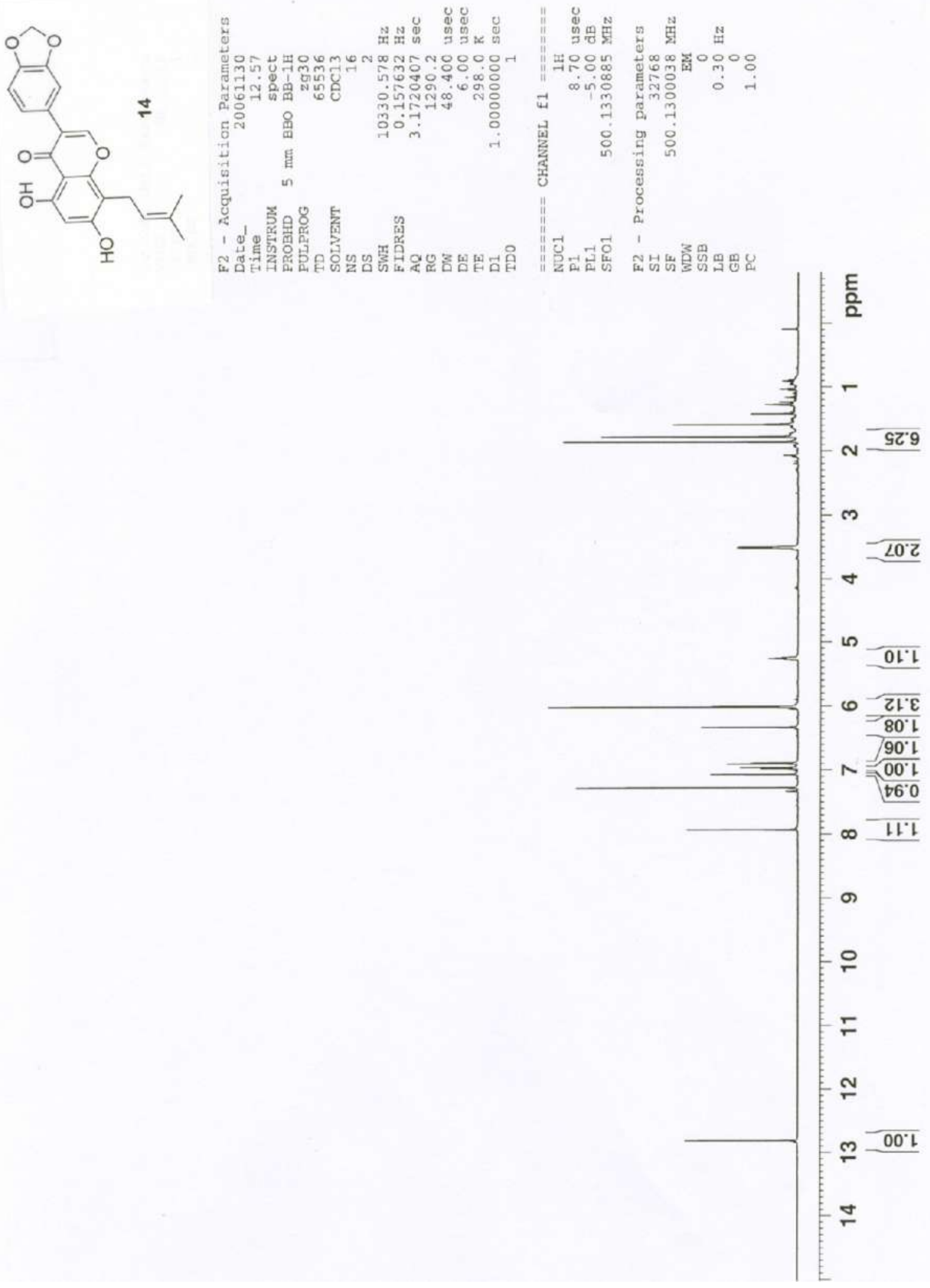

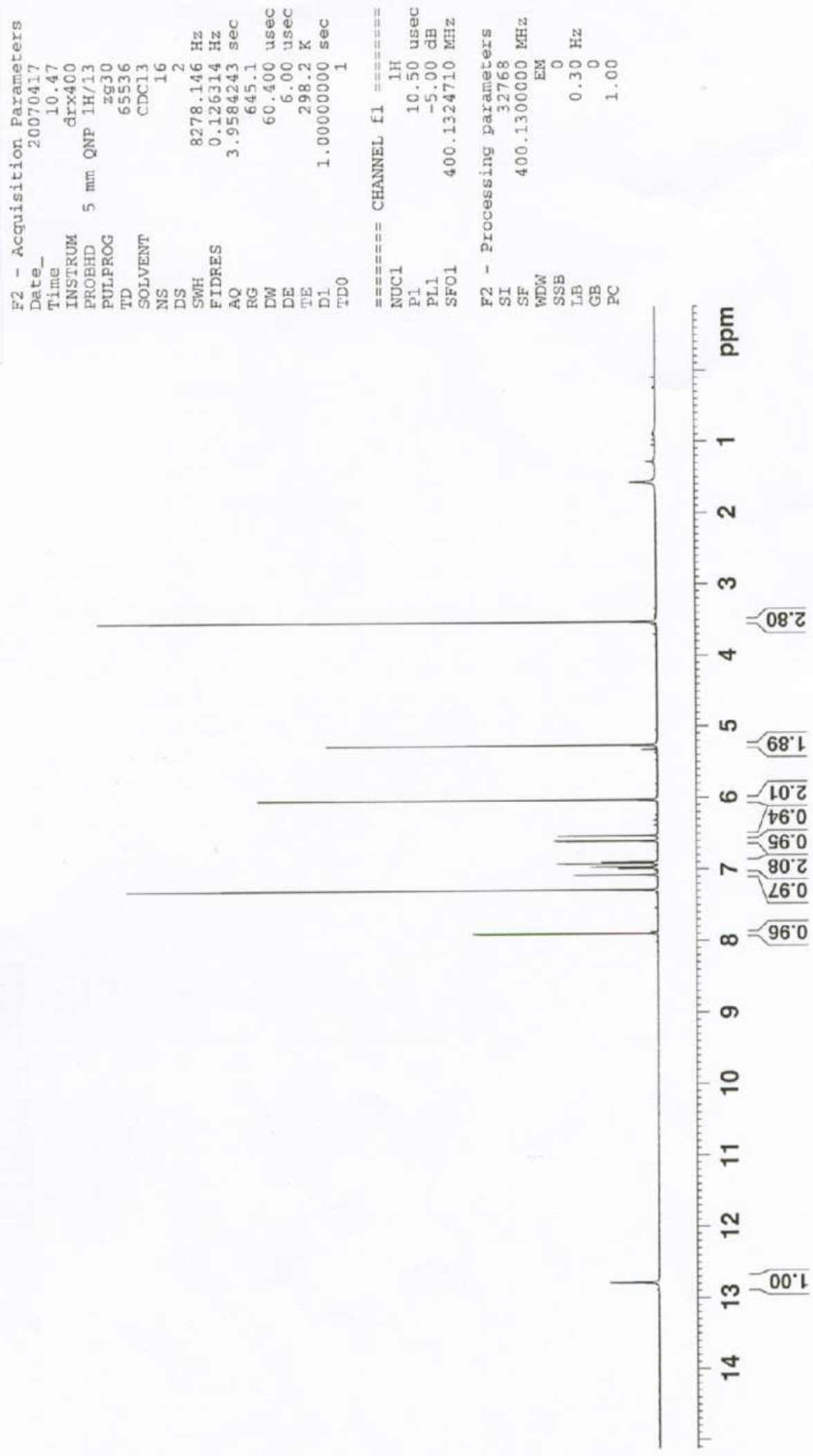


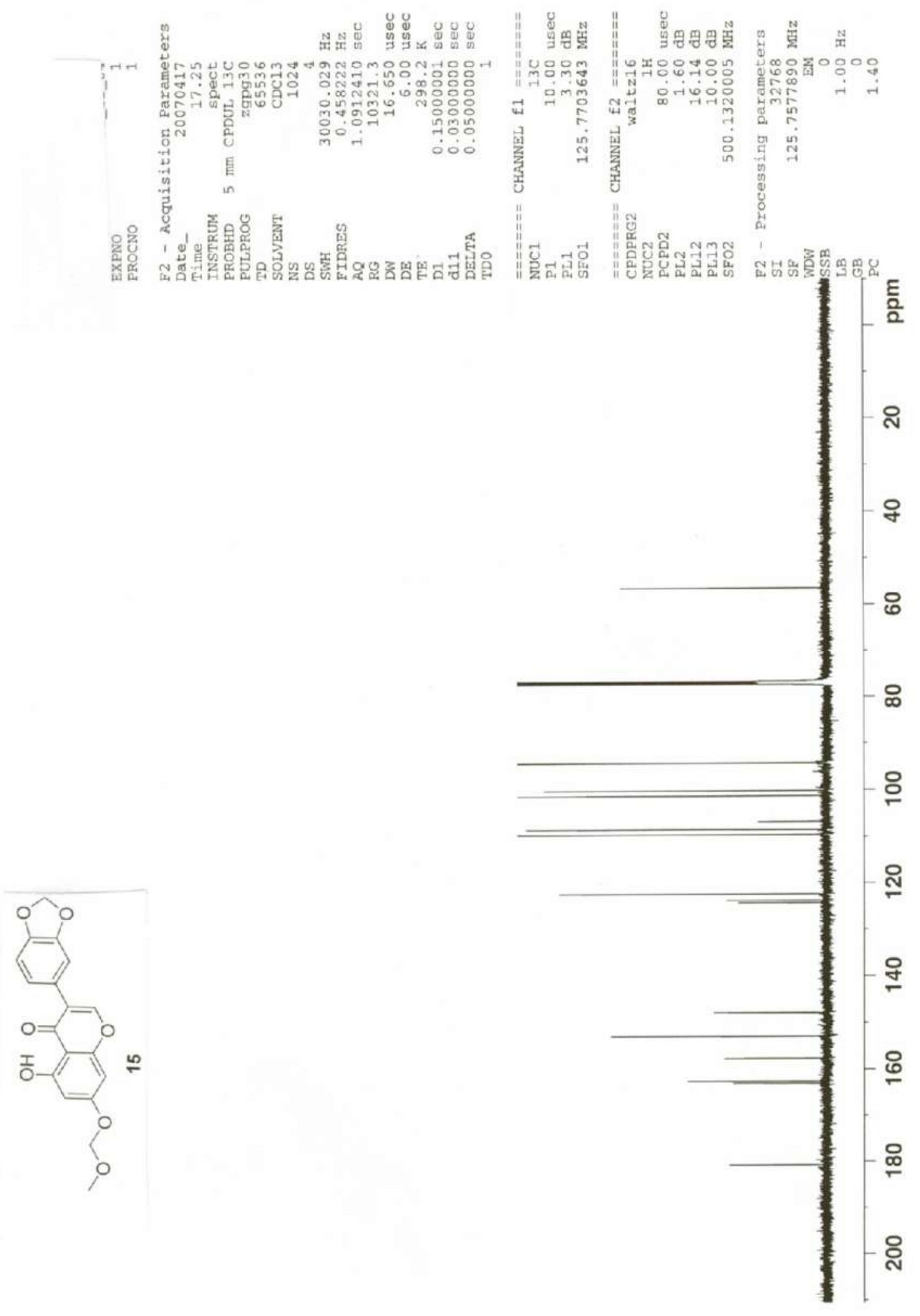



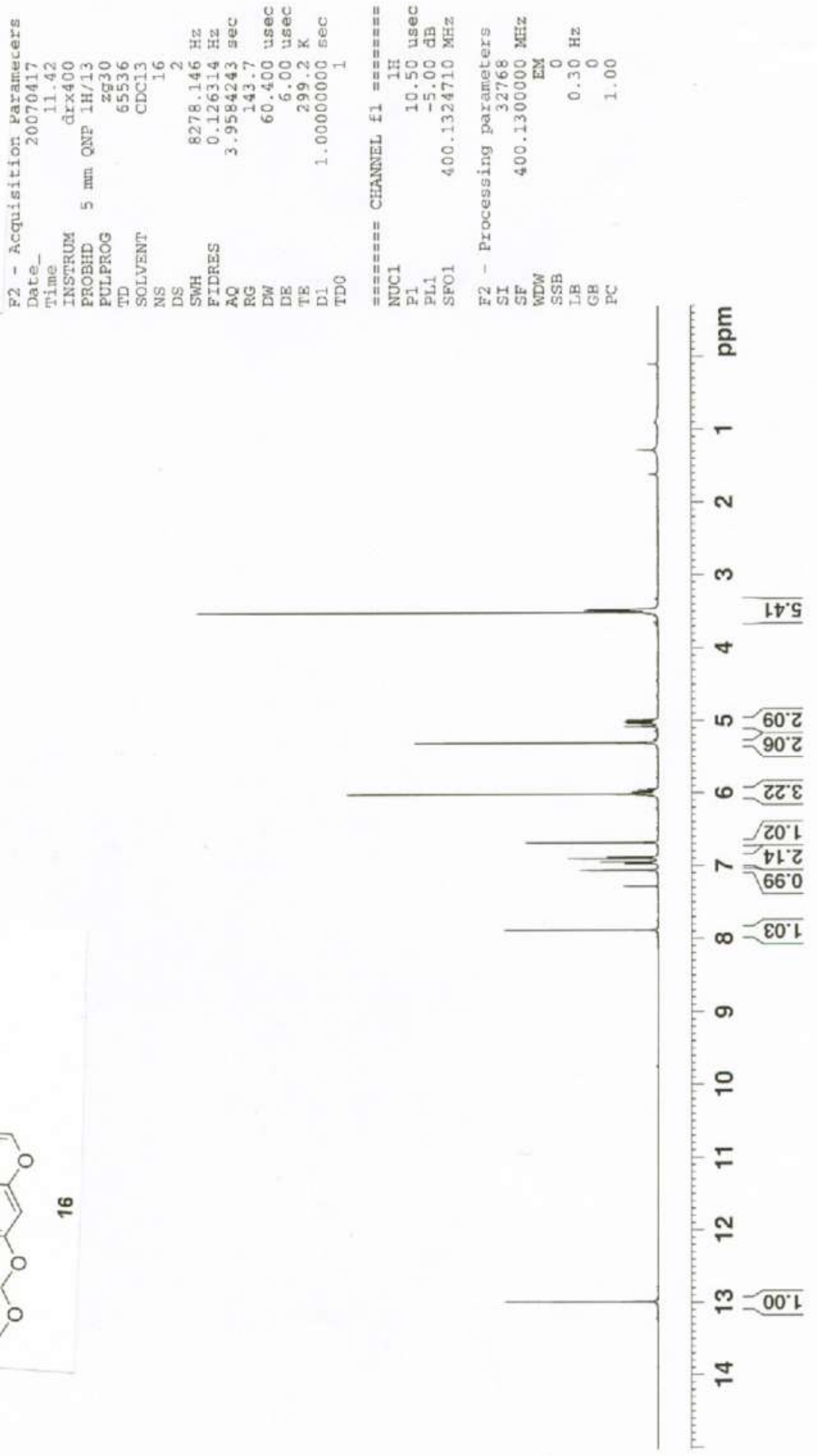


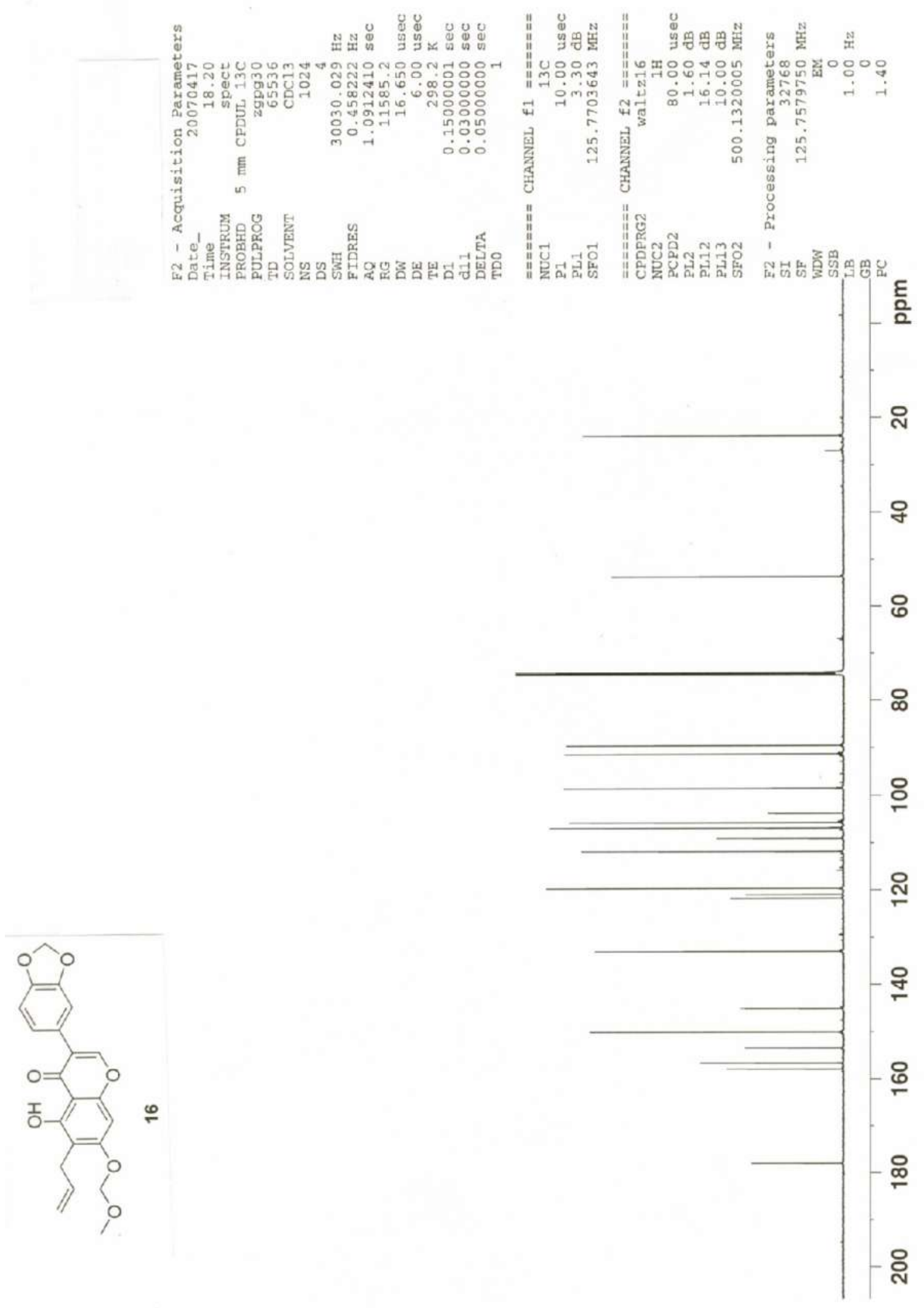




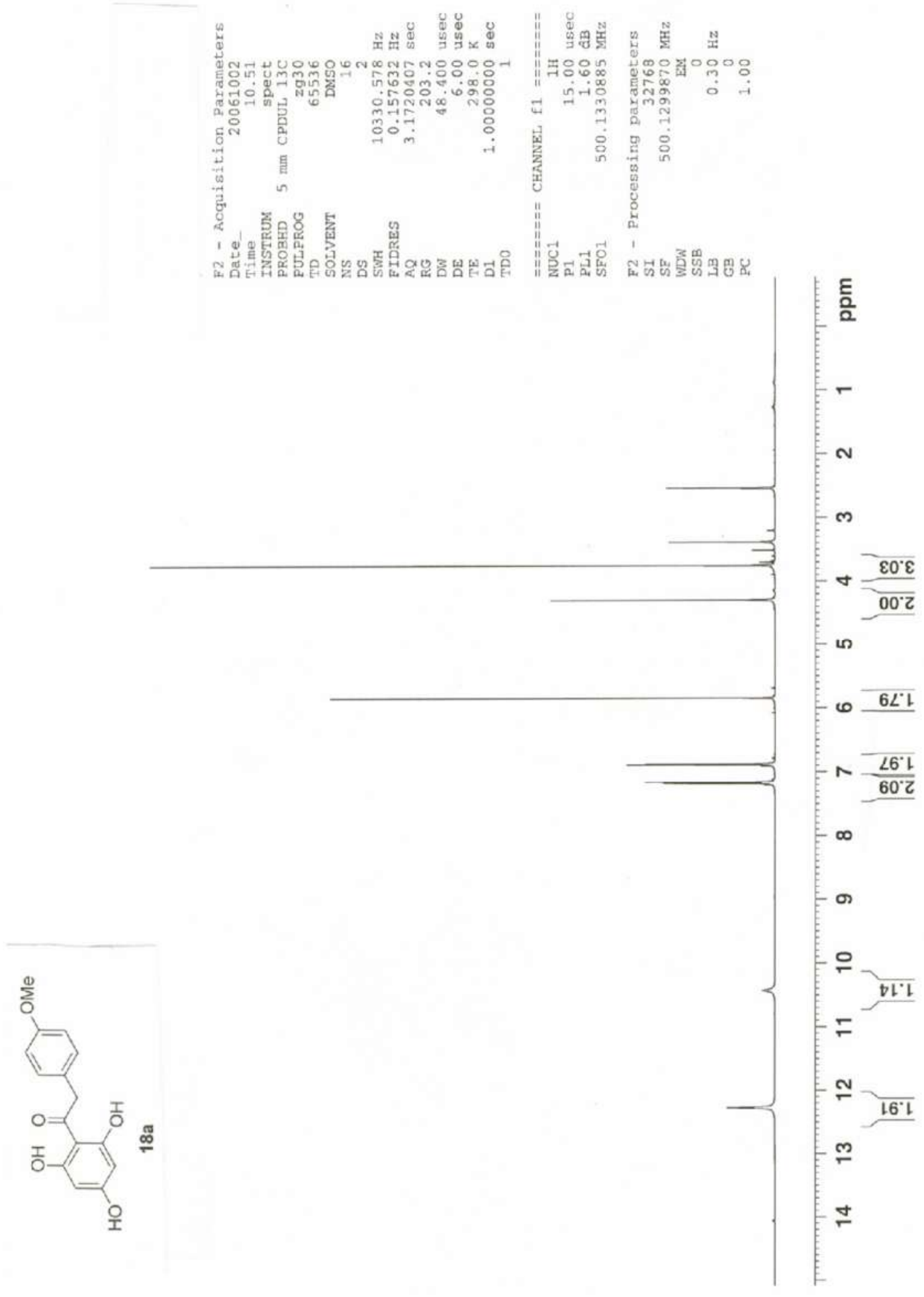




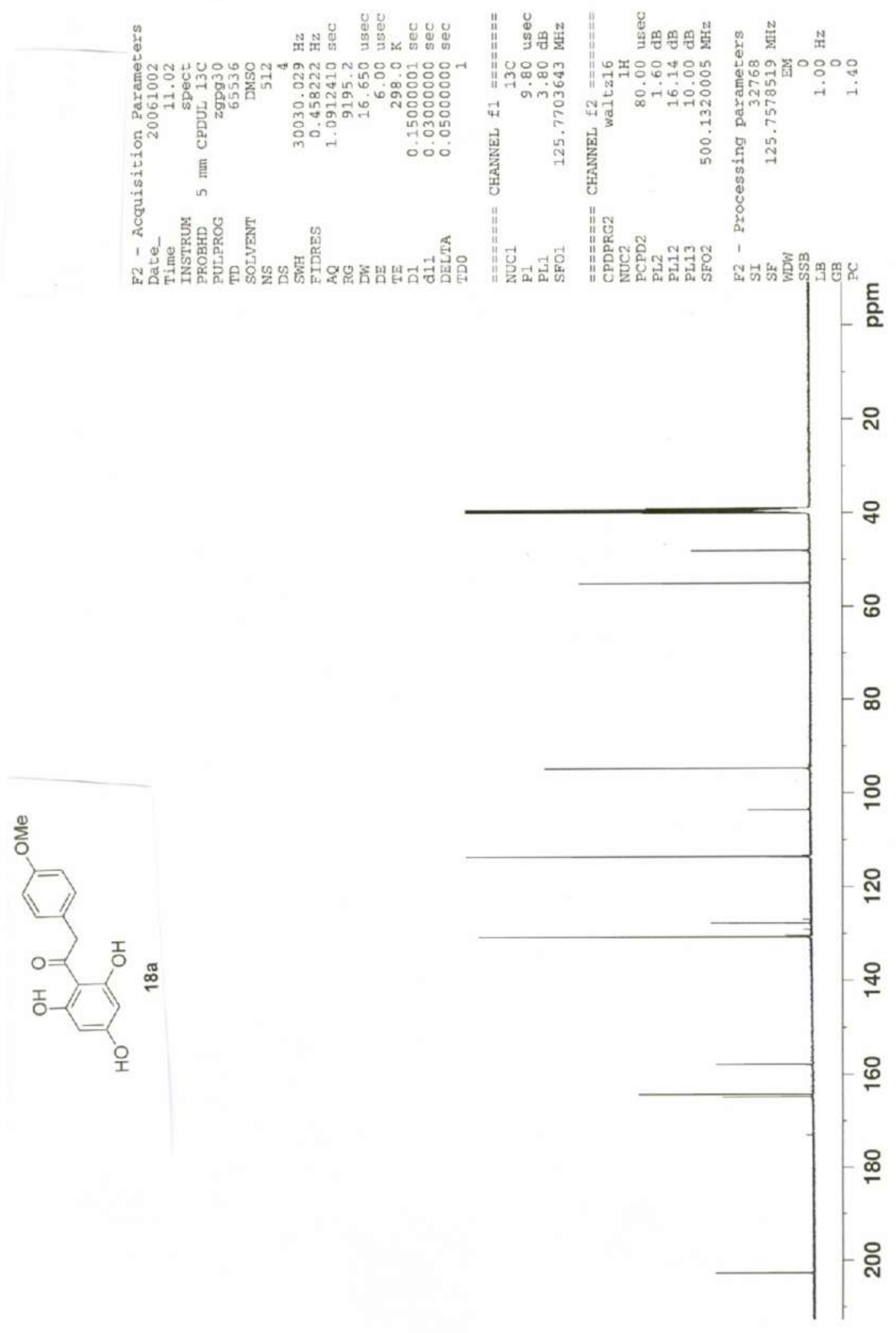



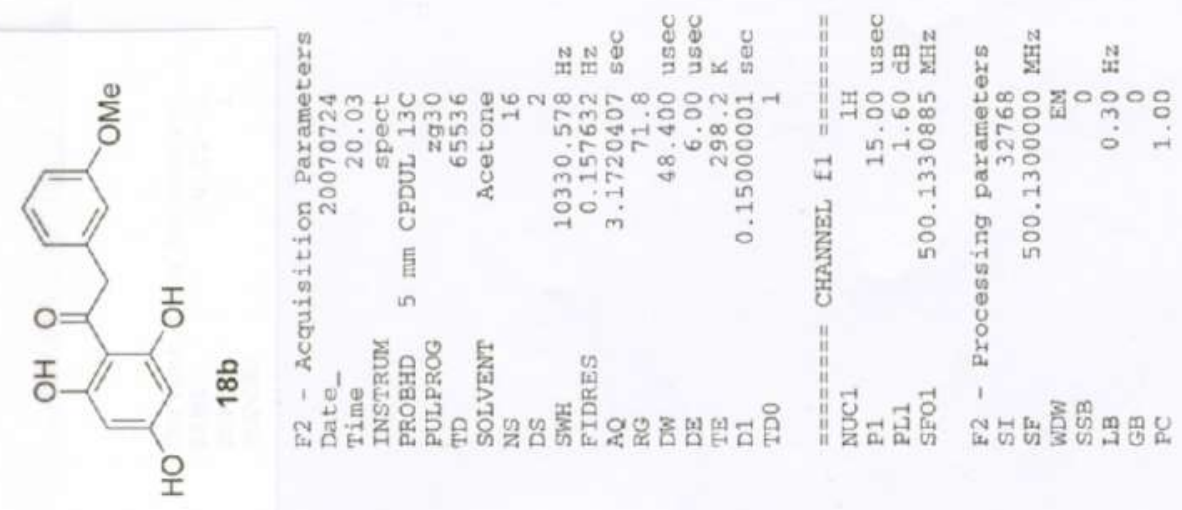

틀

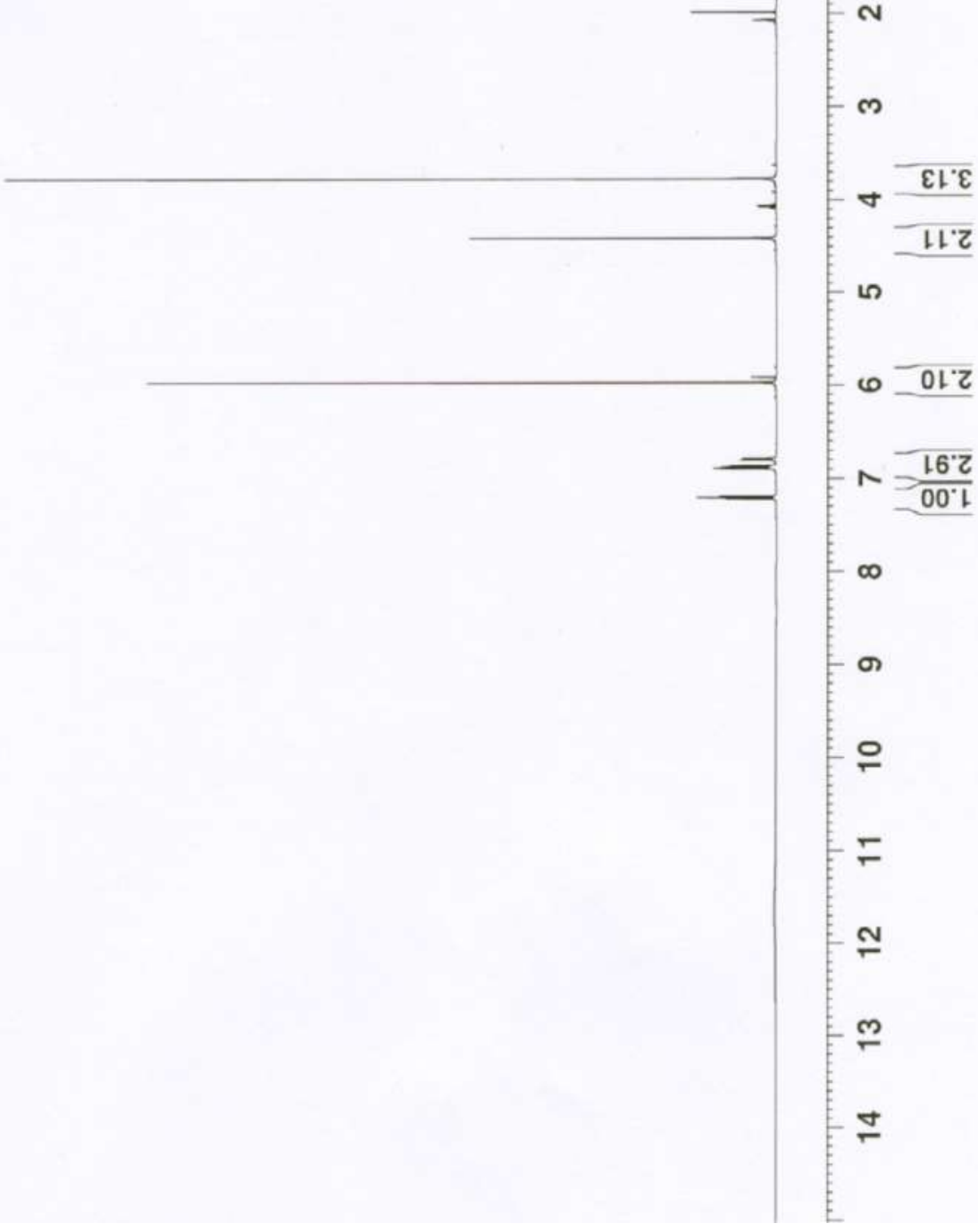



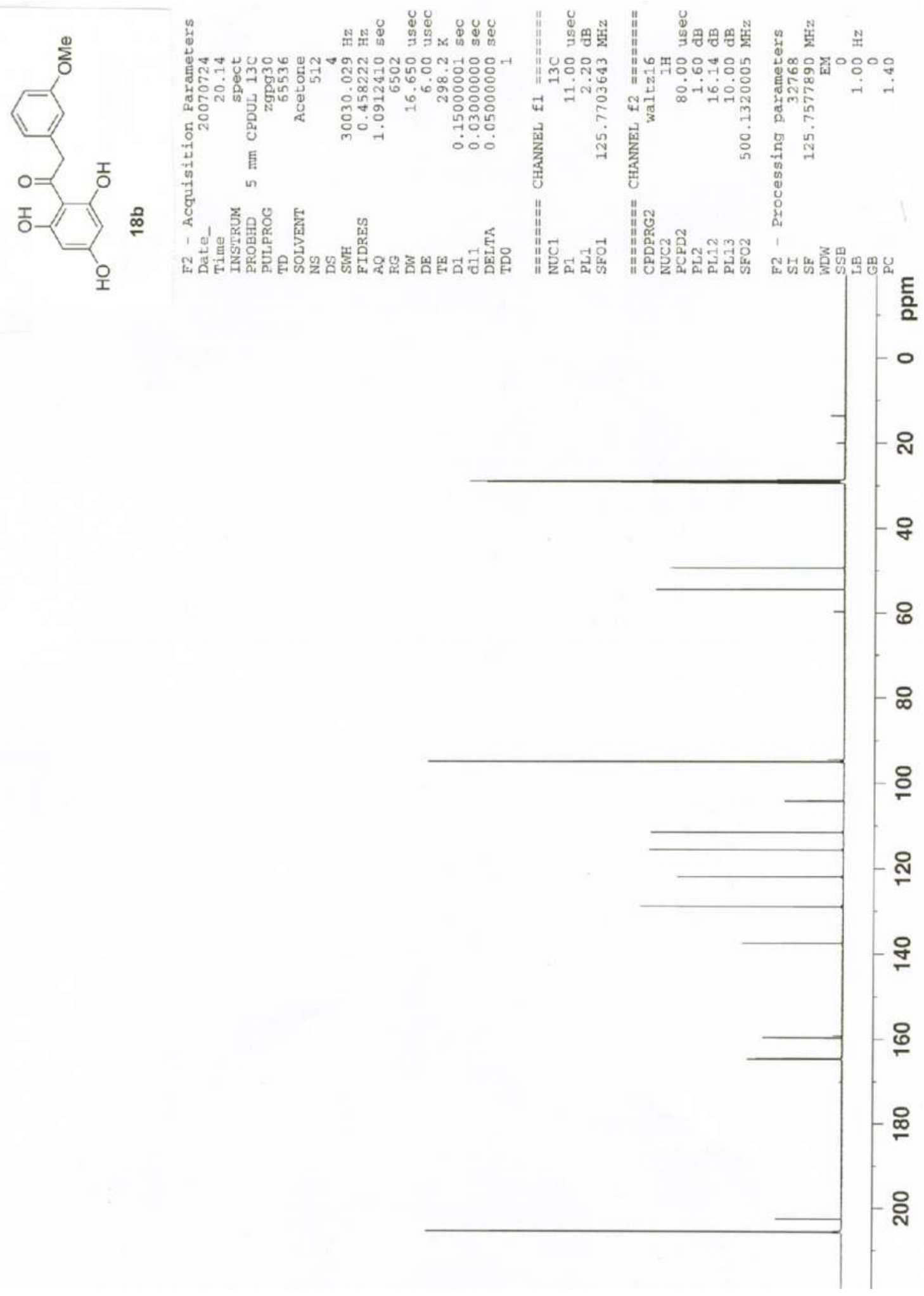

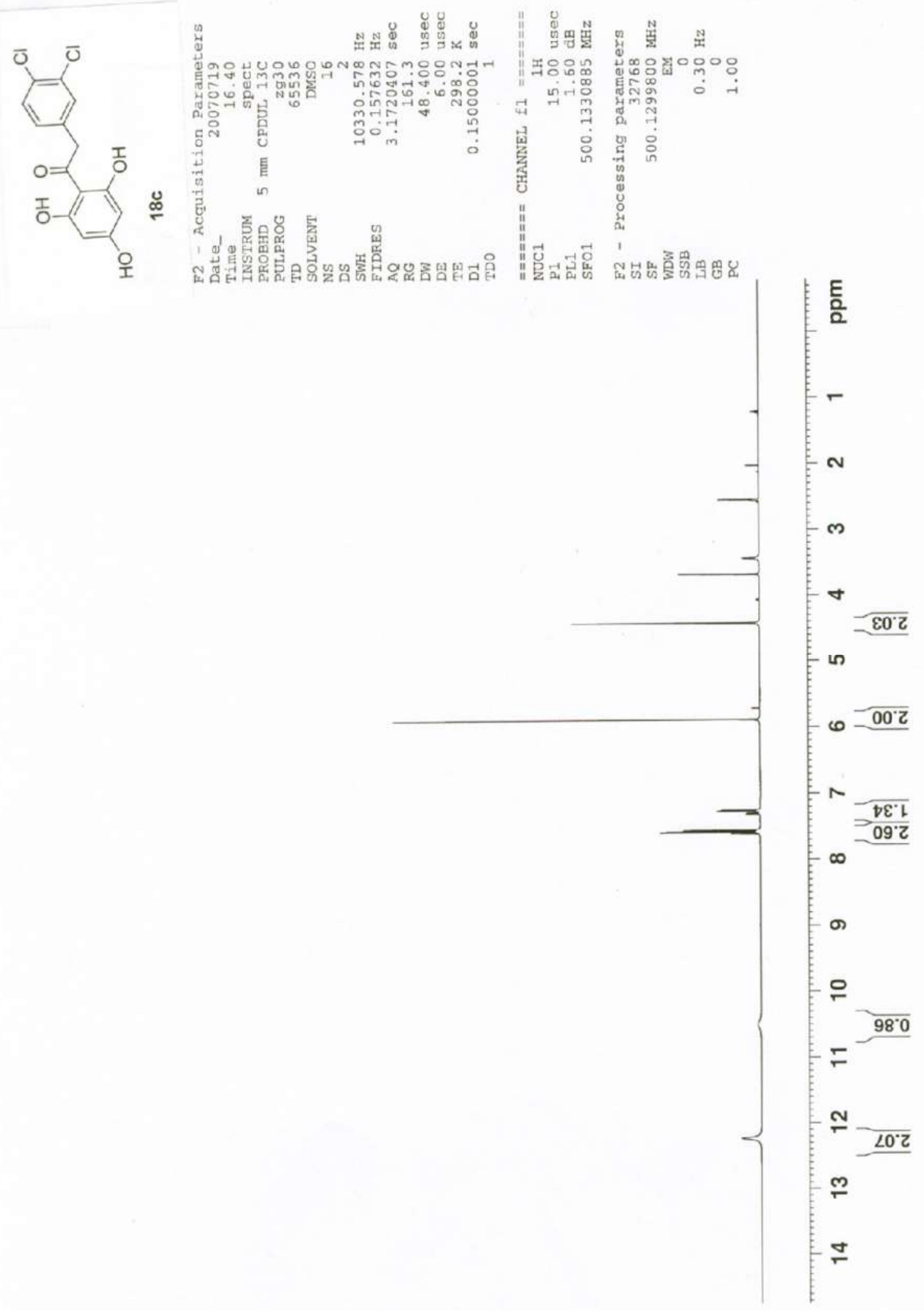

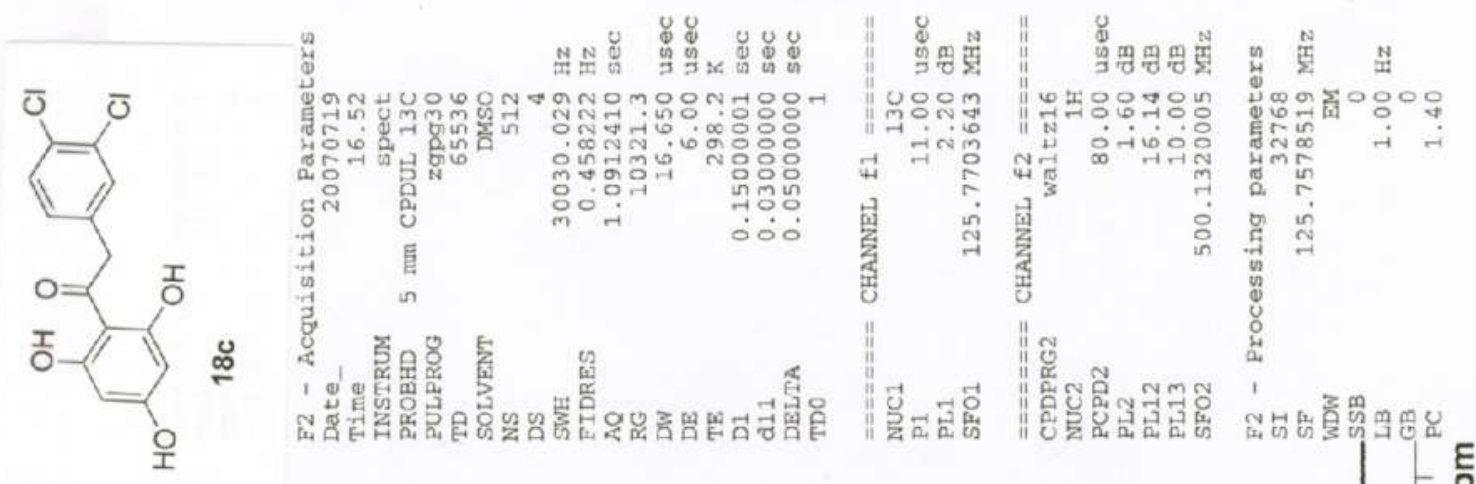

틈

ํํ

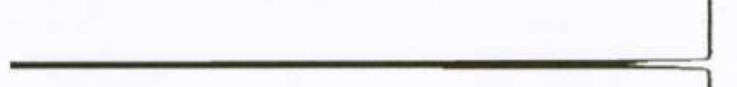

우

우

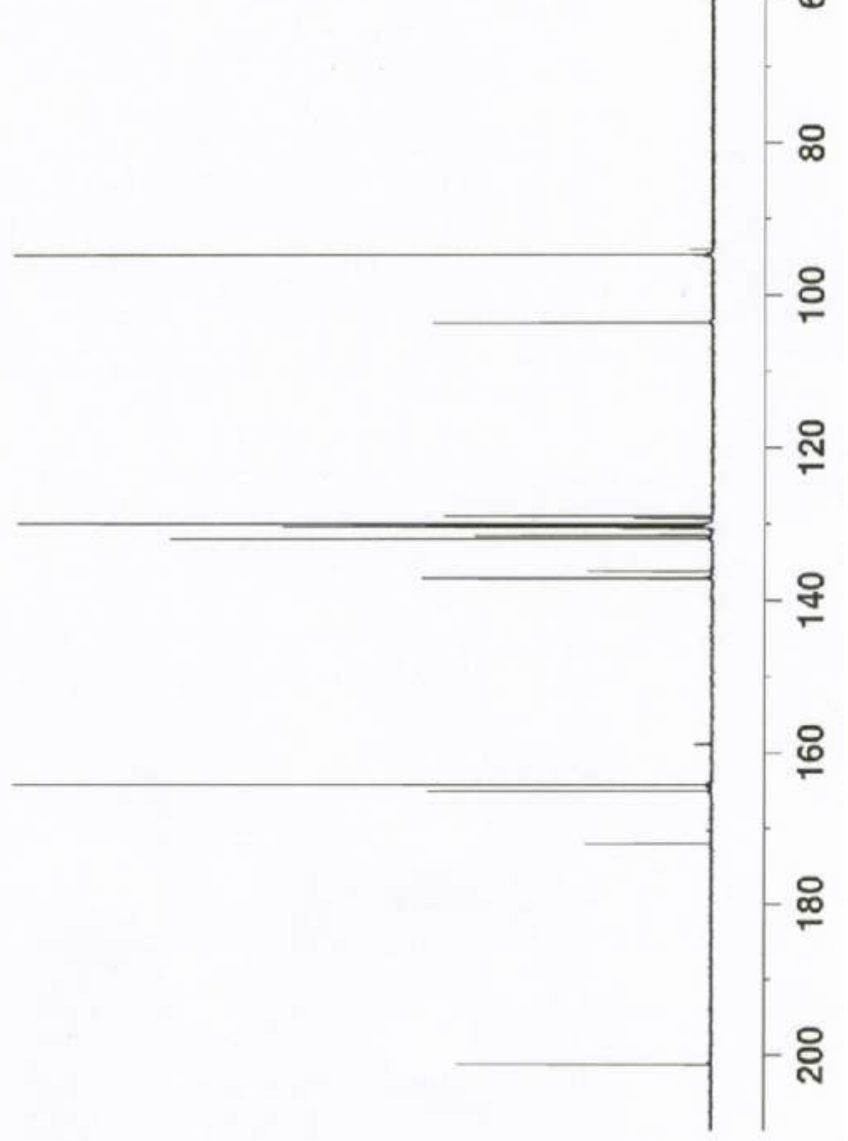



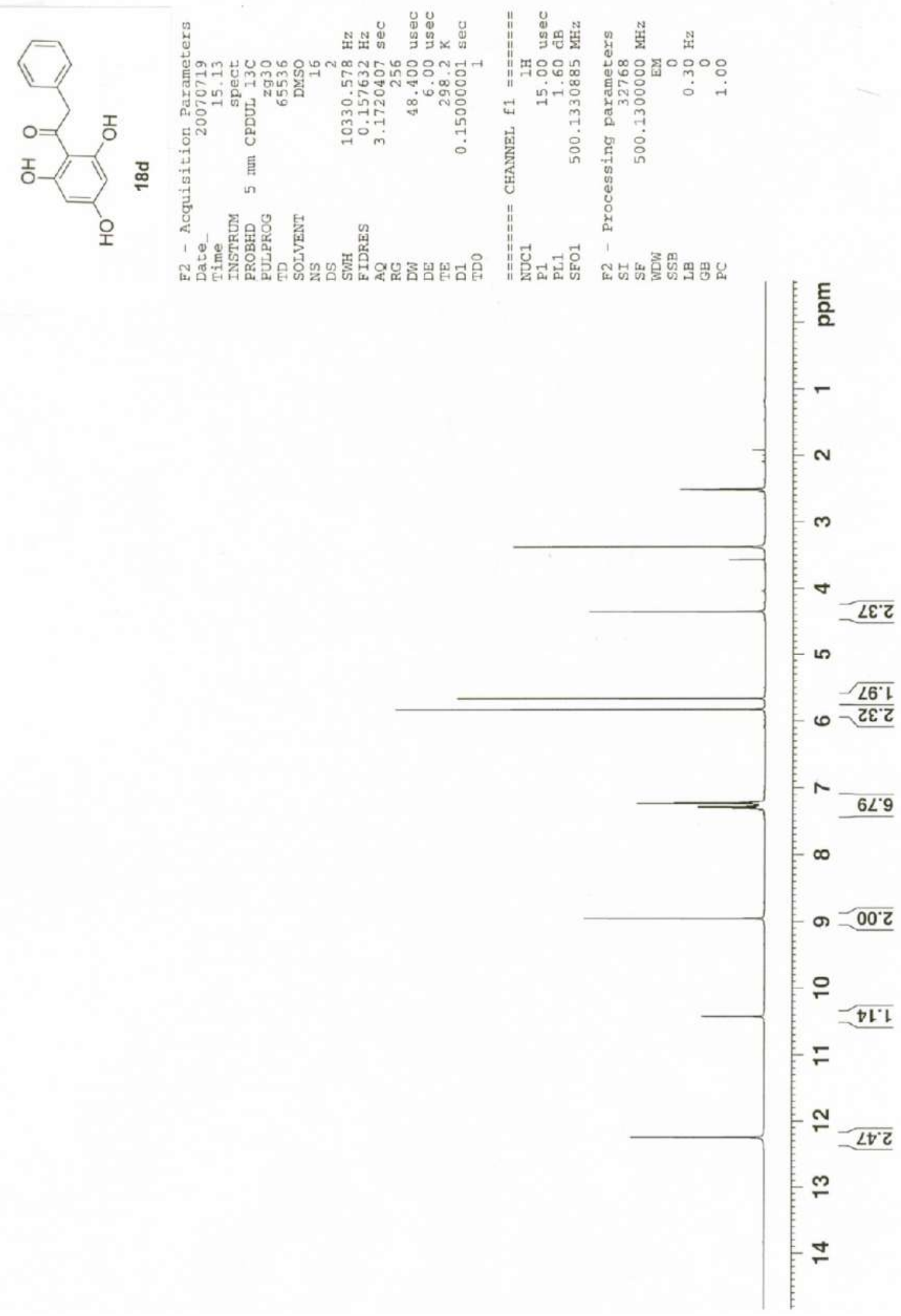

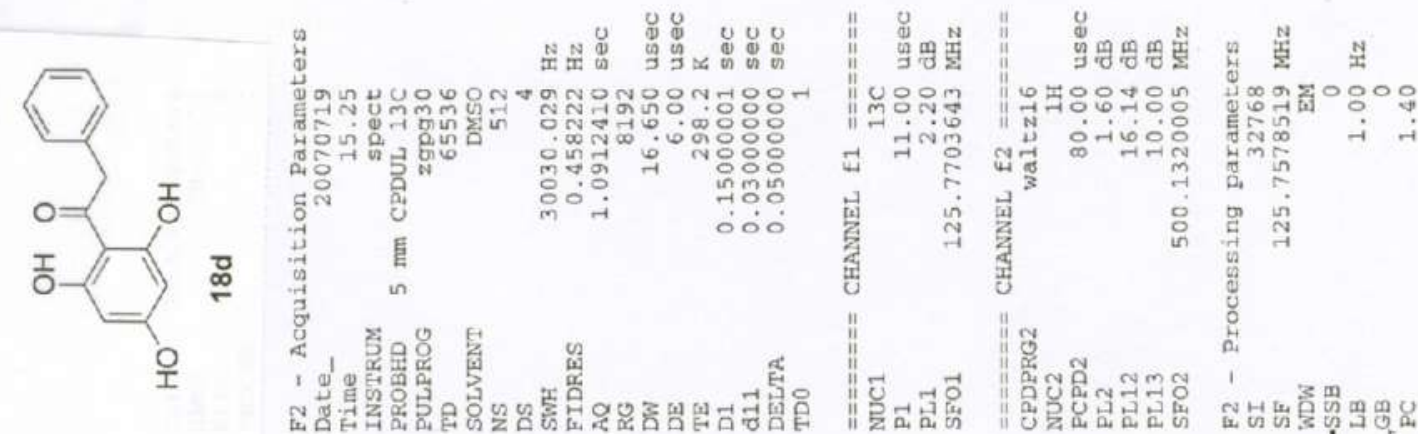
웝.

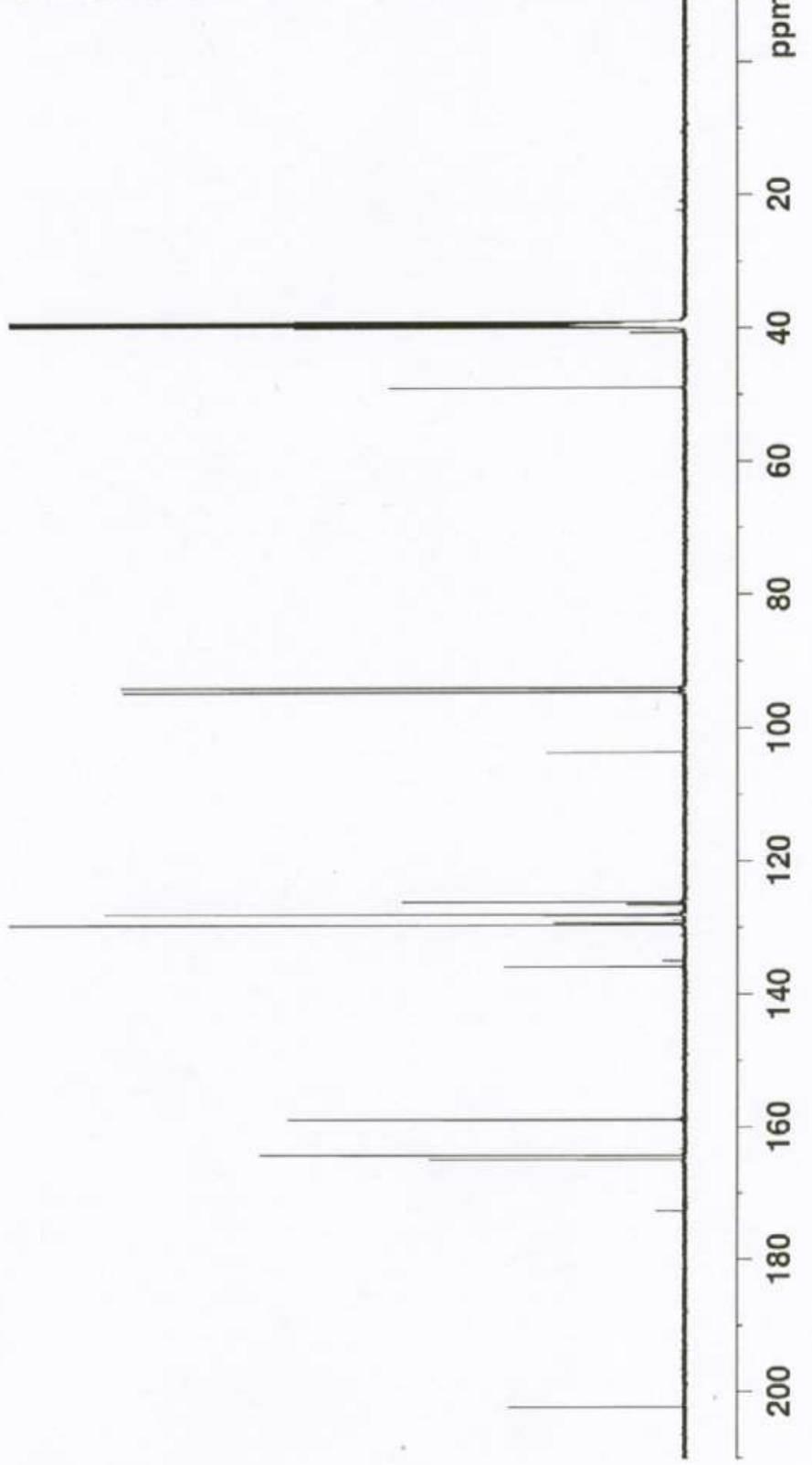



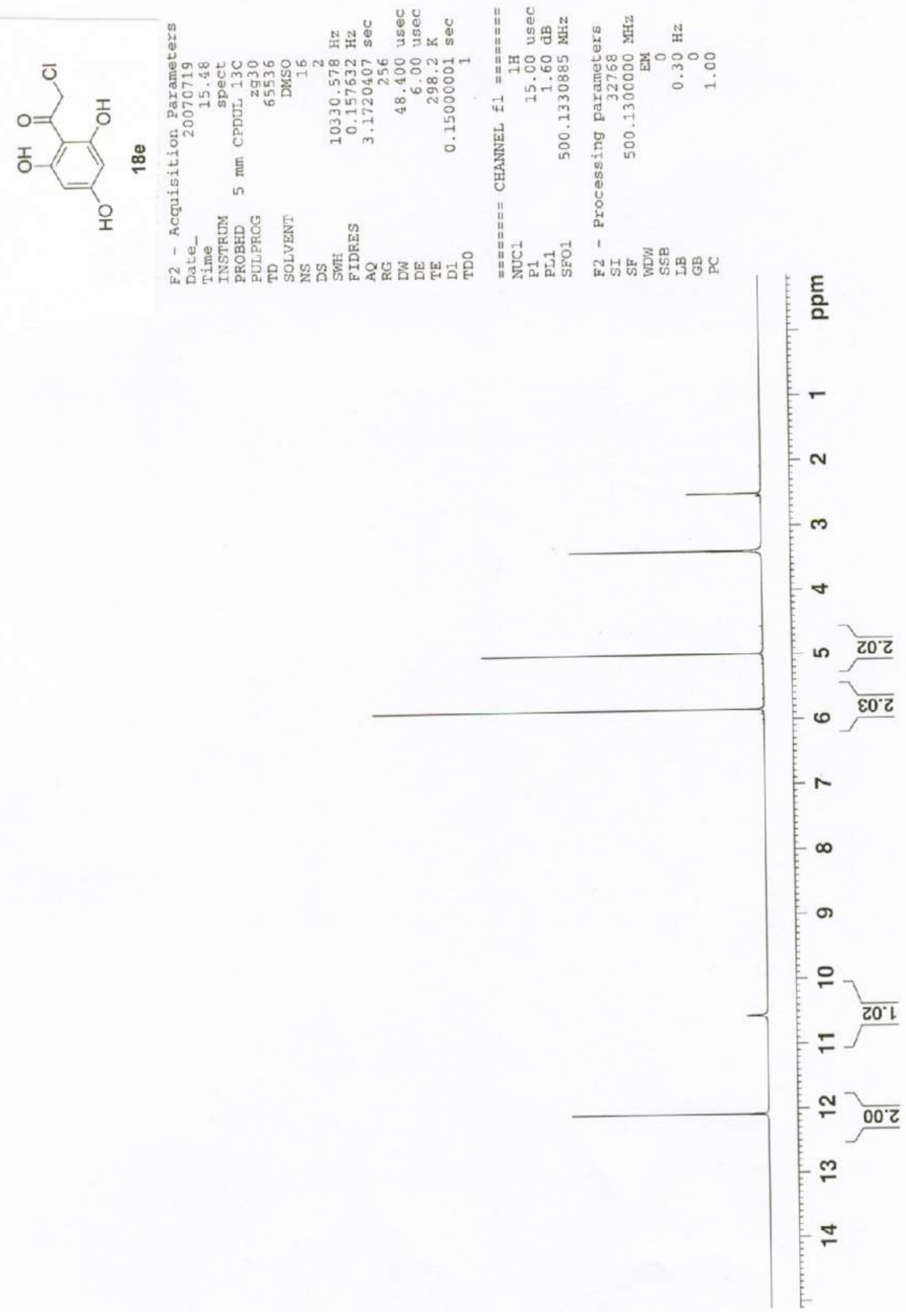


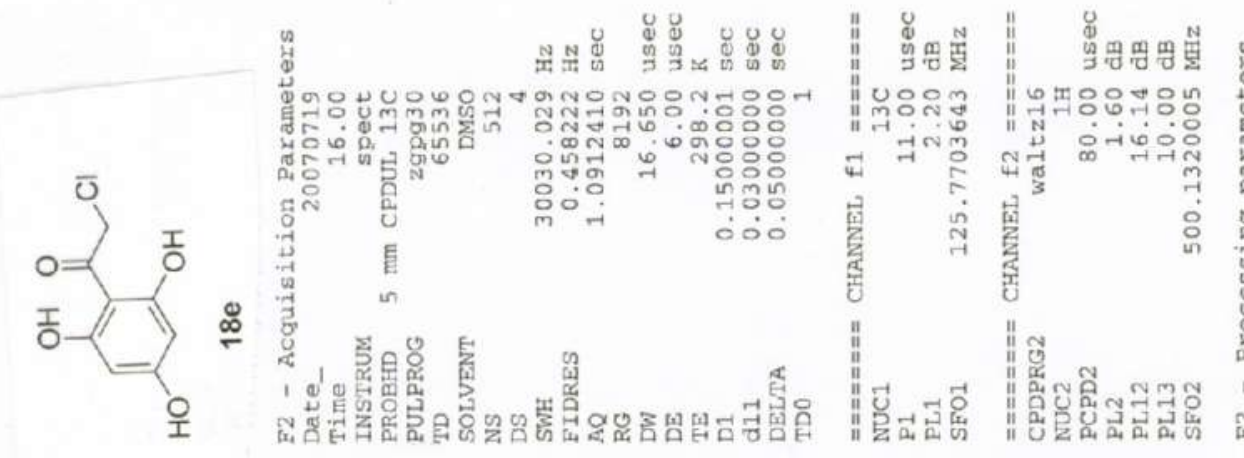

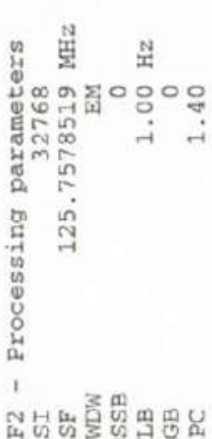

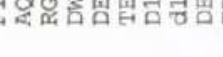

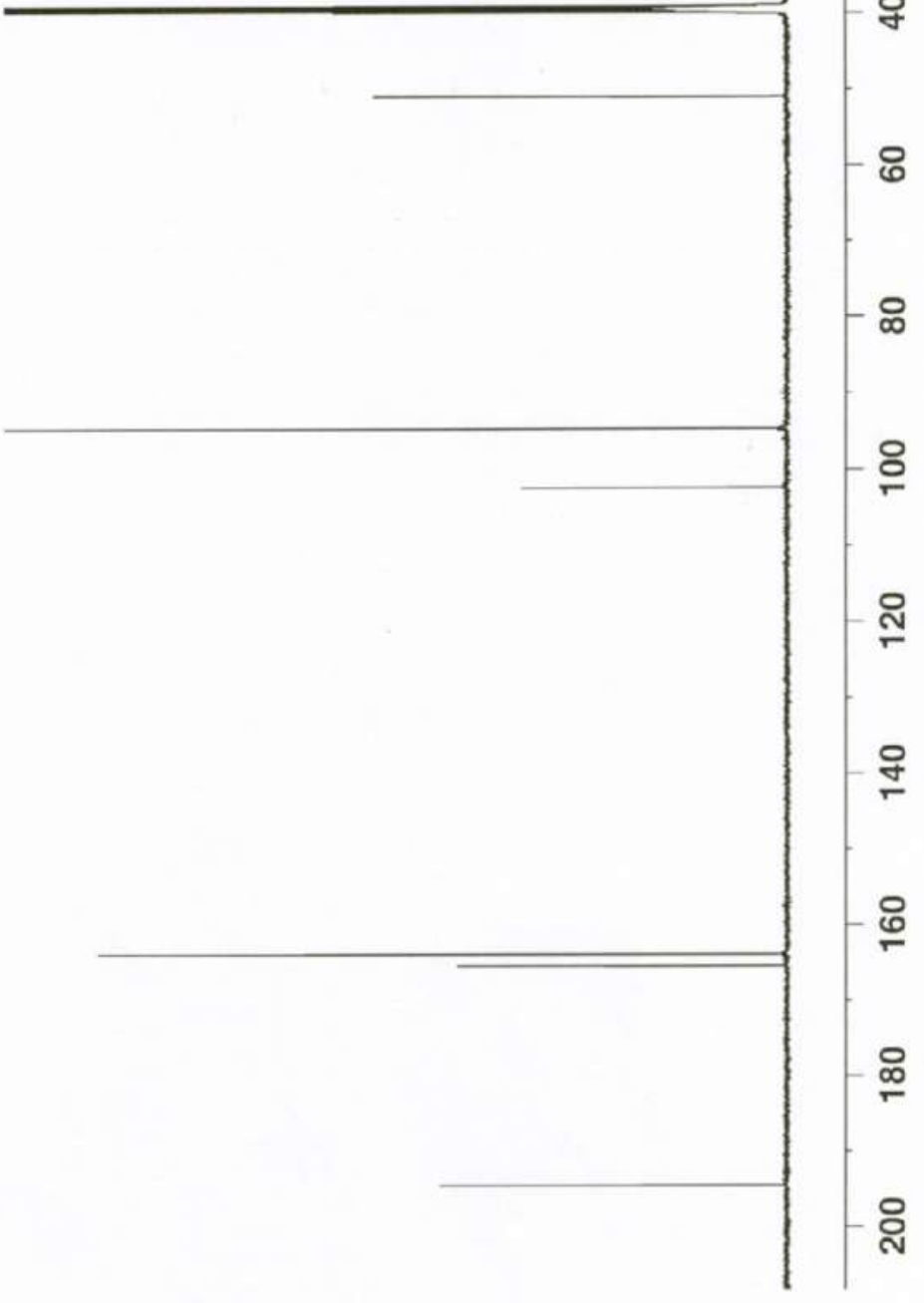




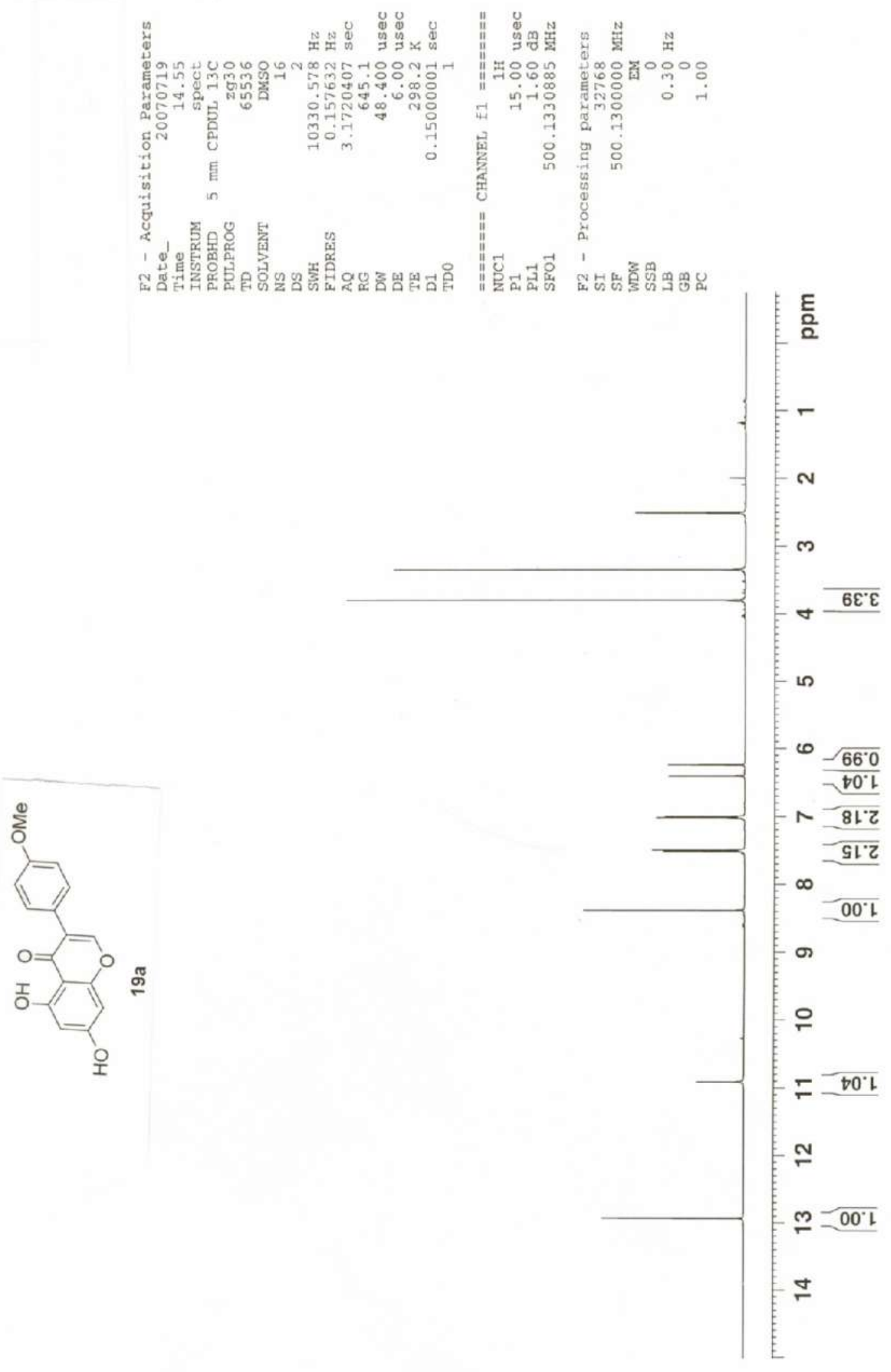




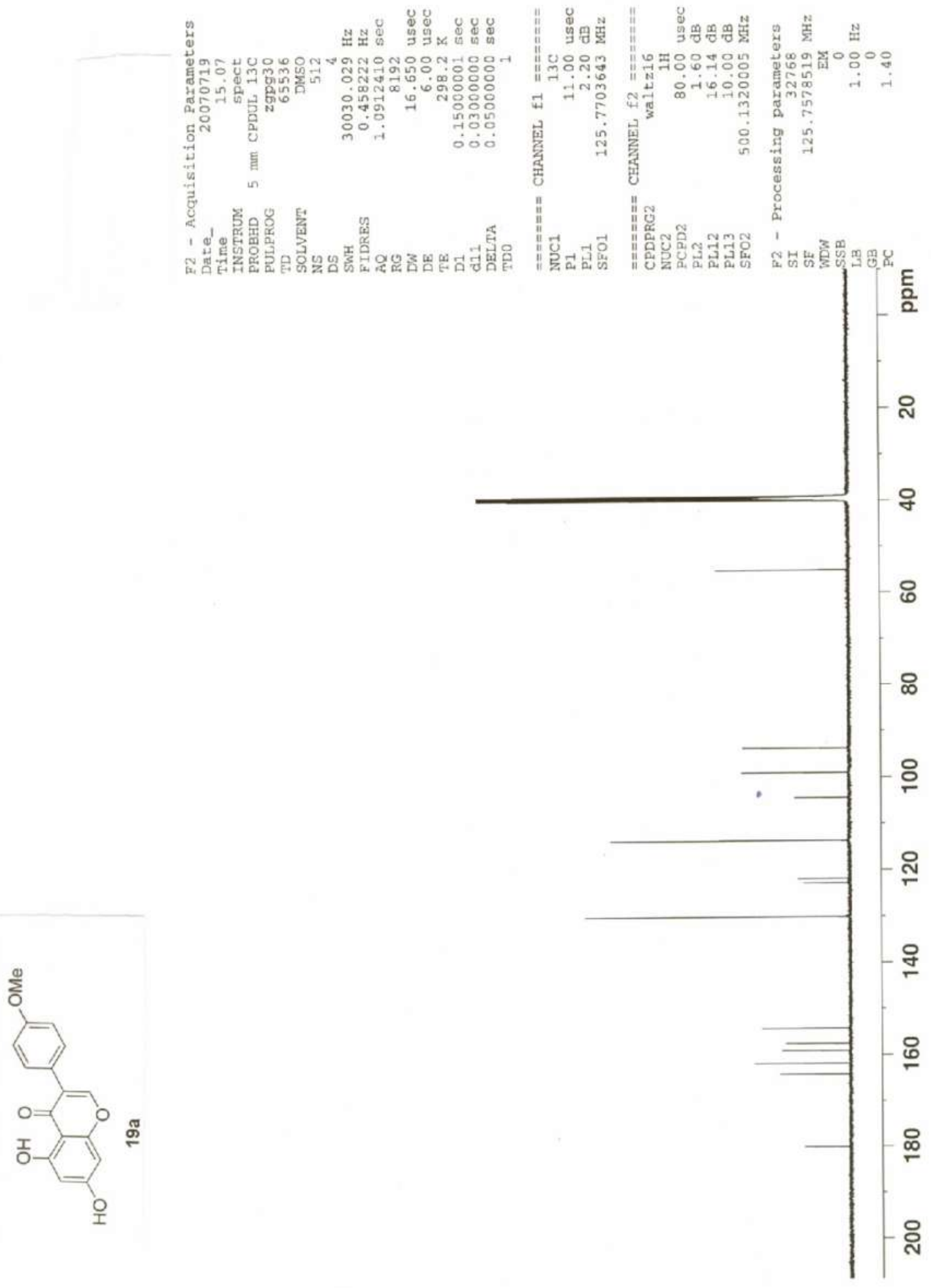




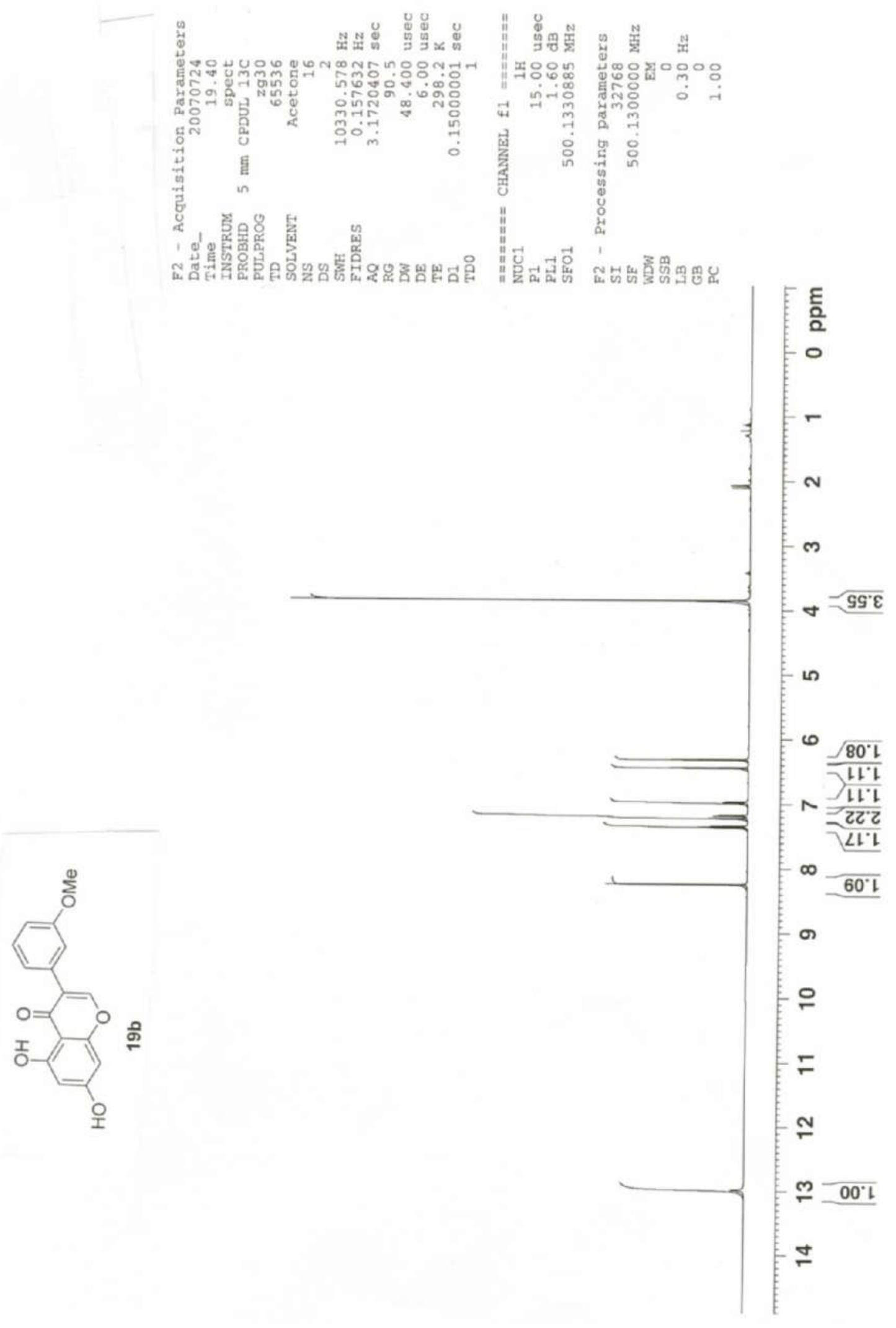




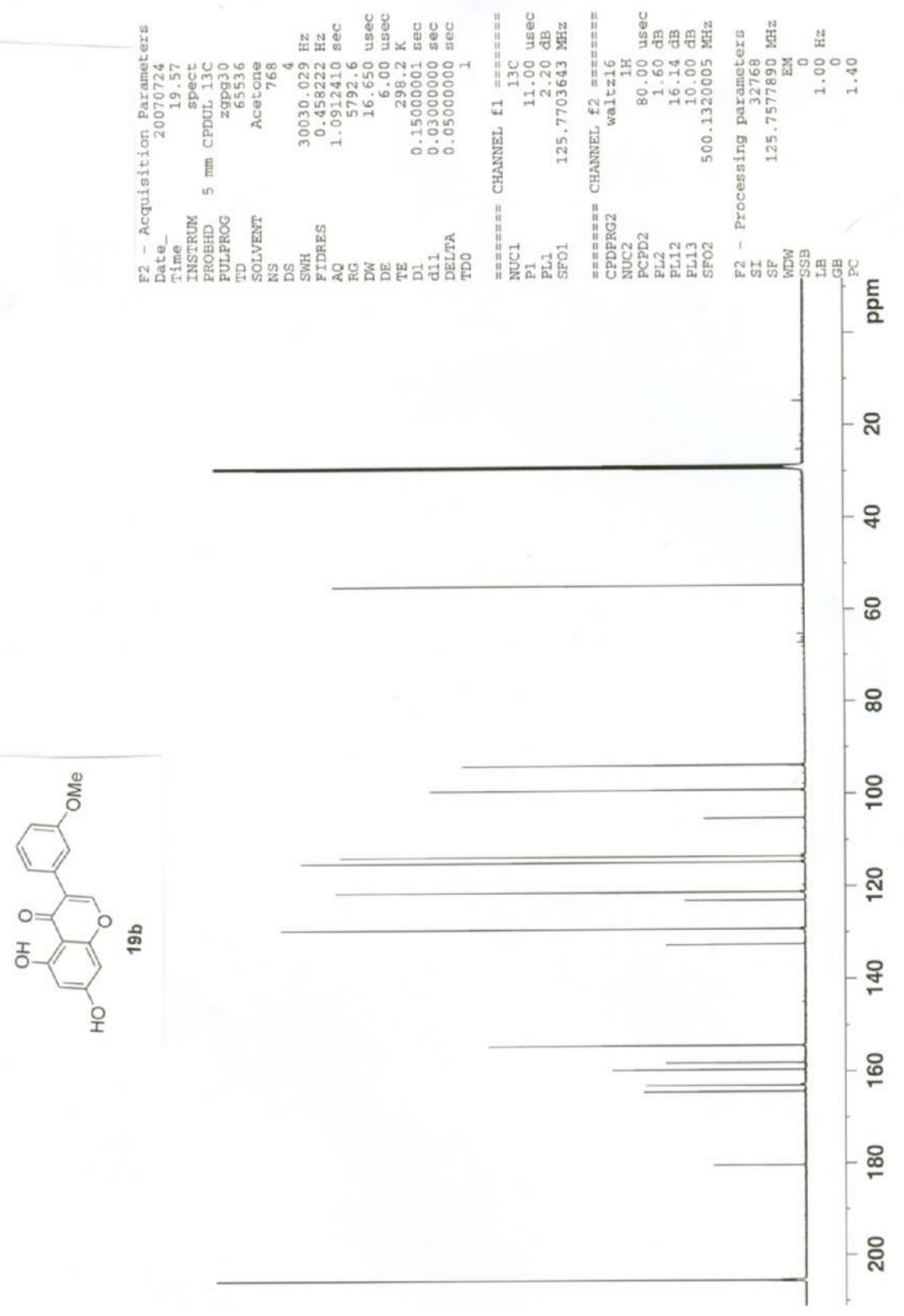




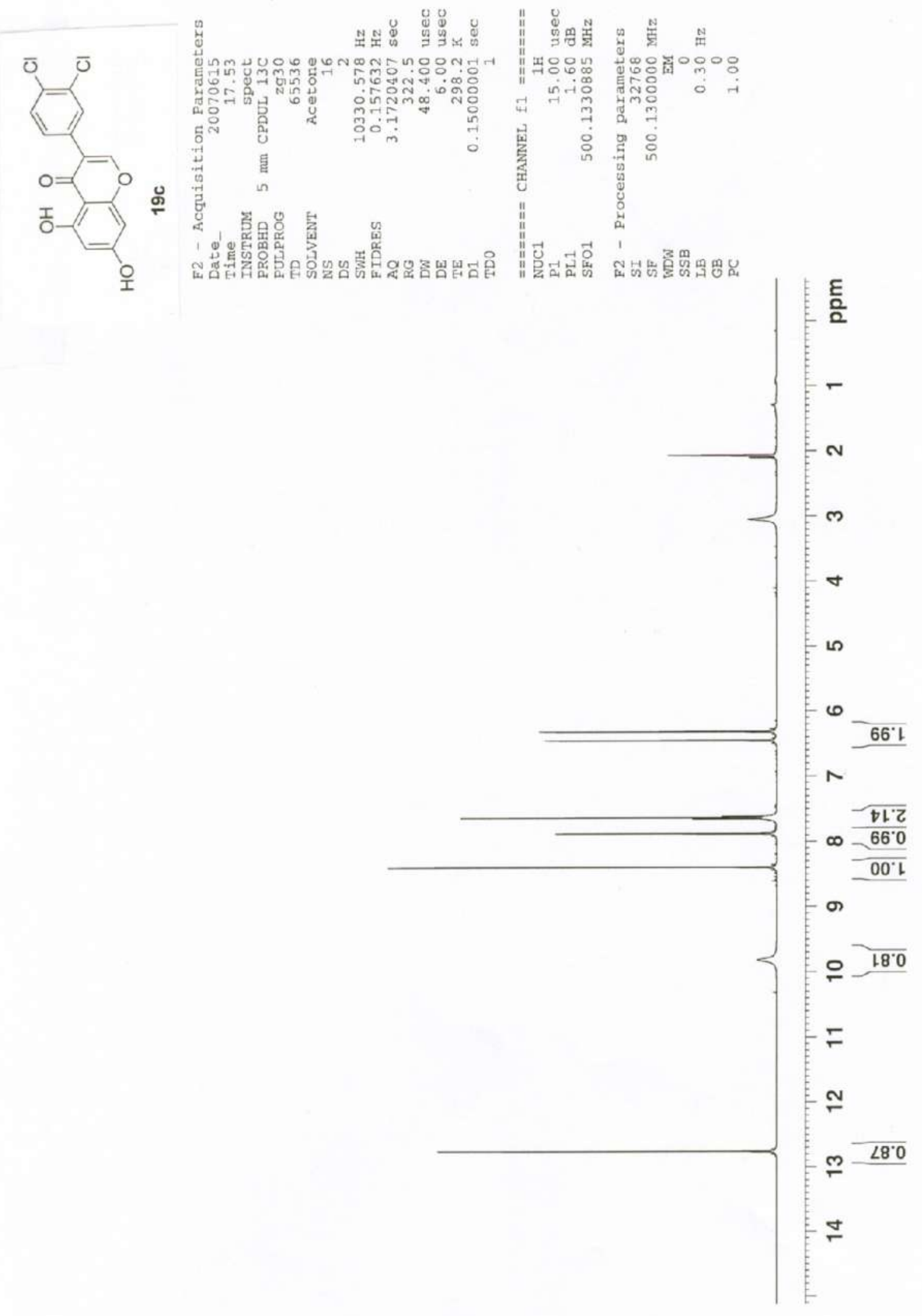



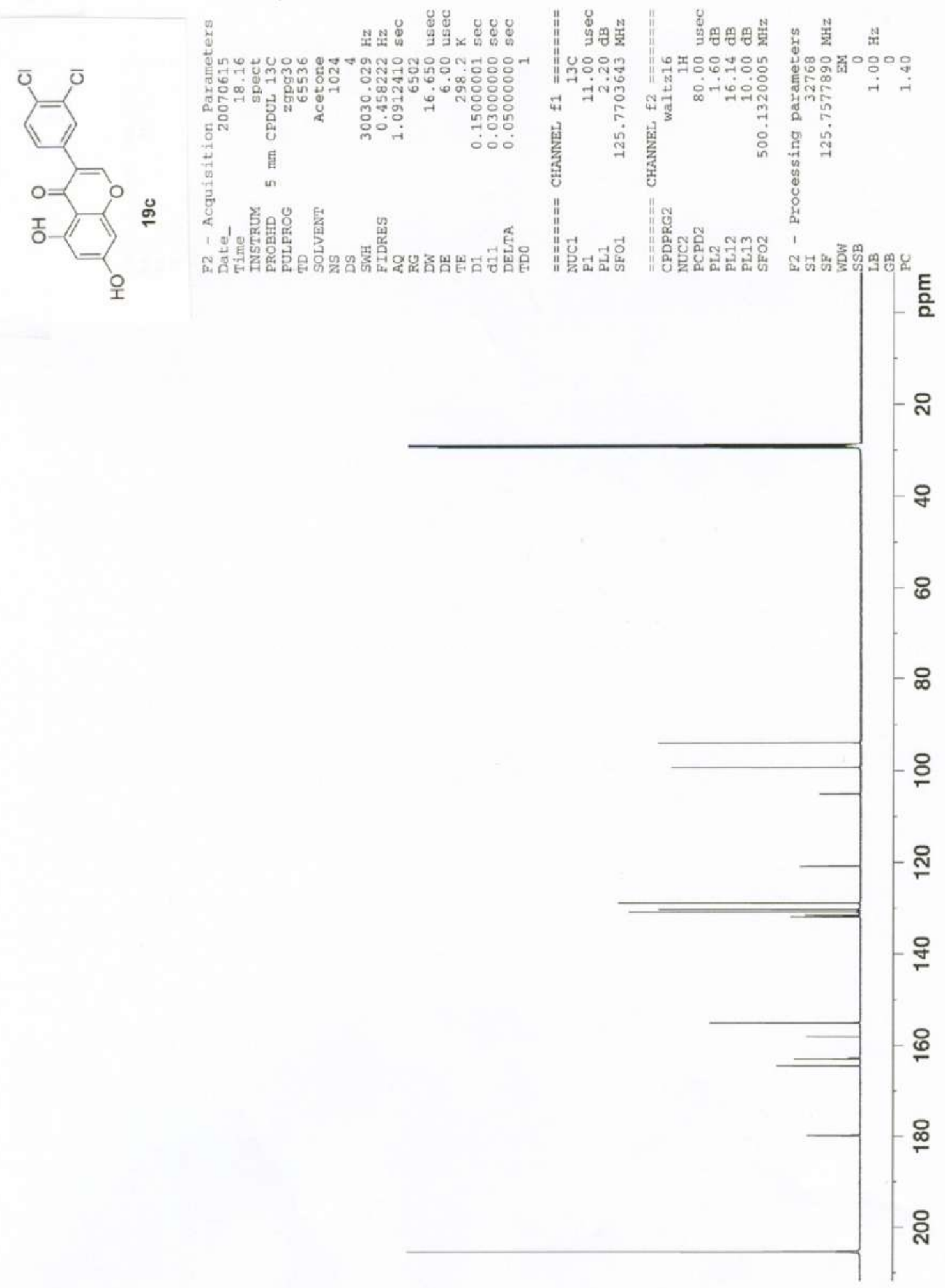

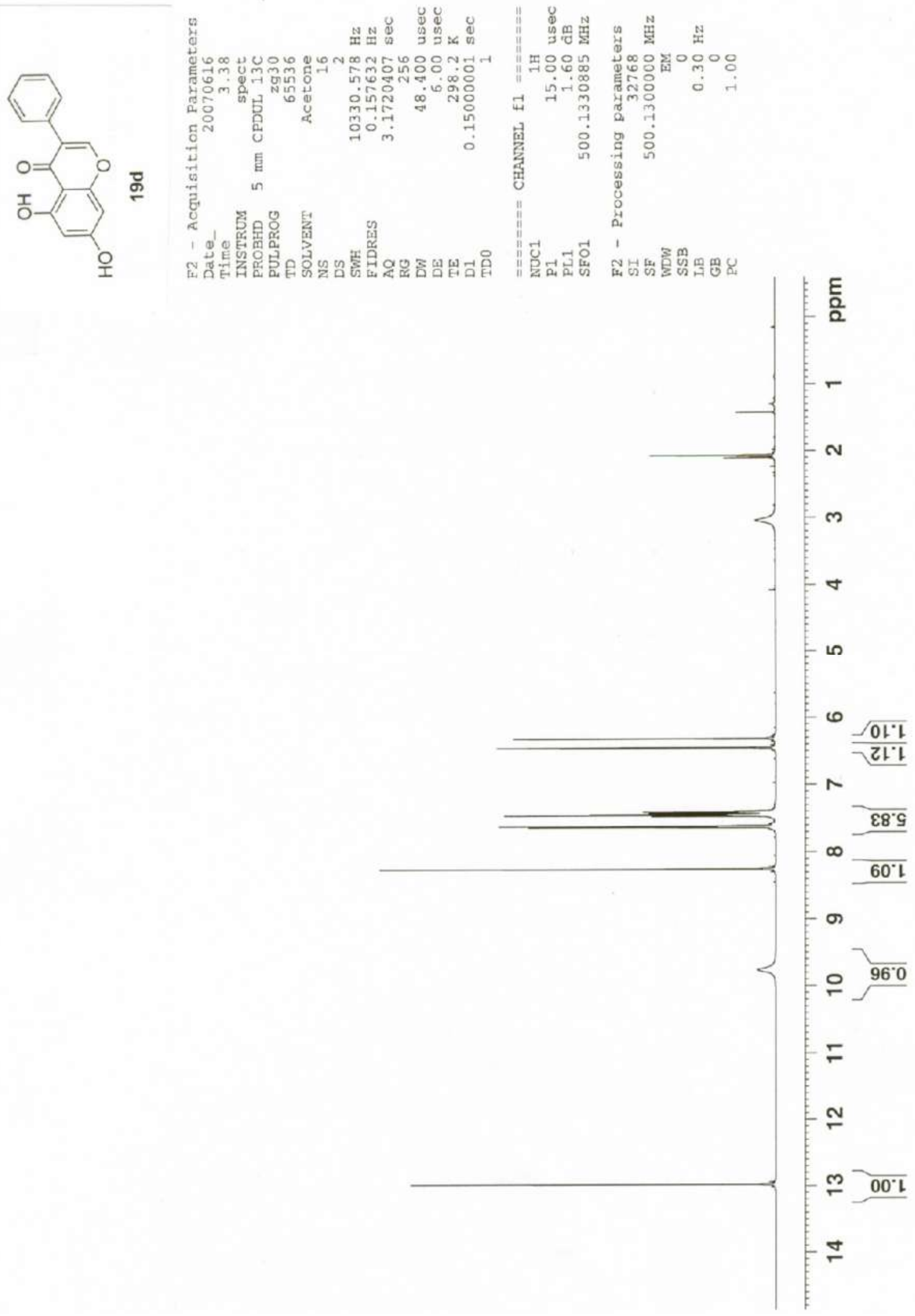

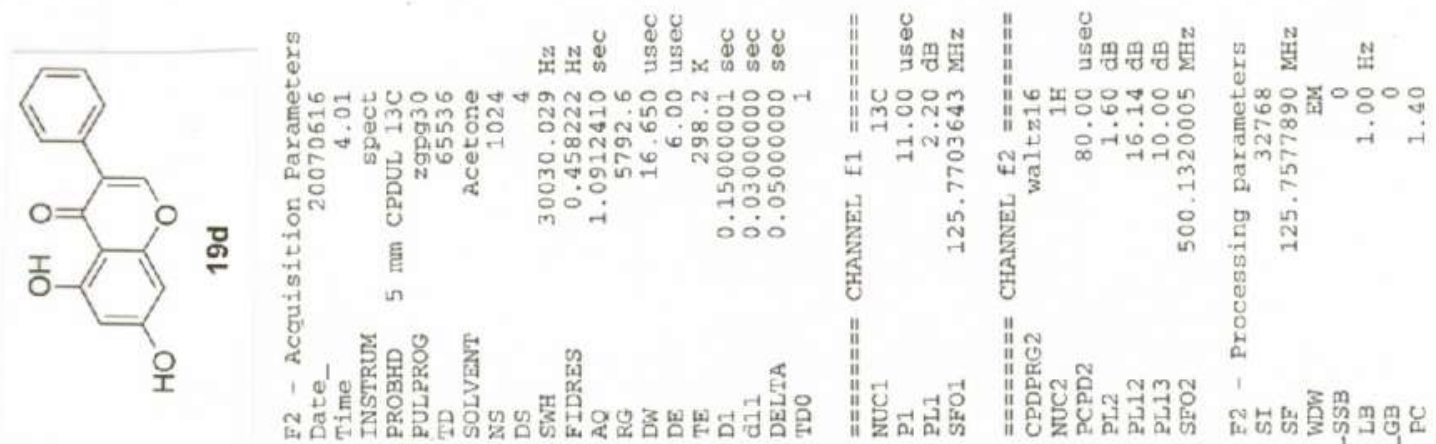

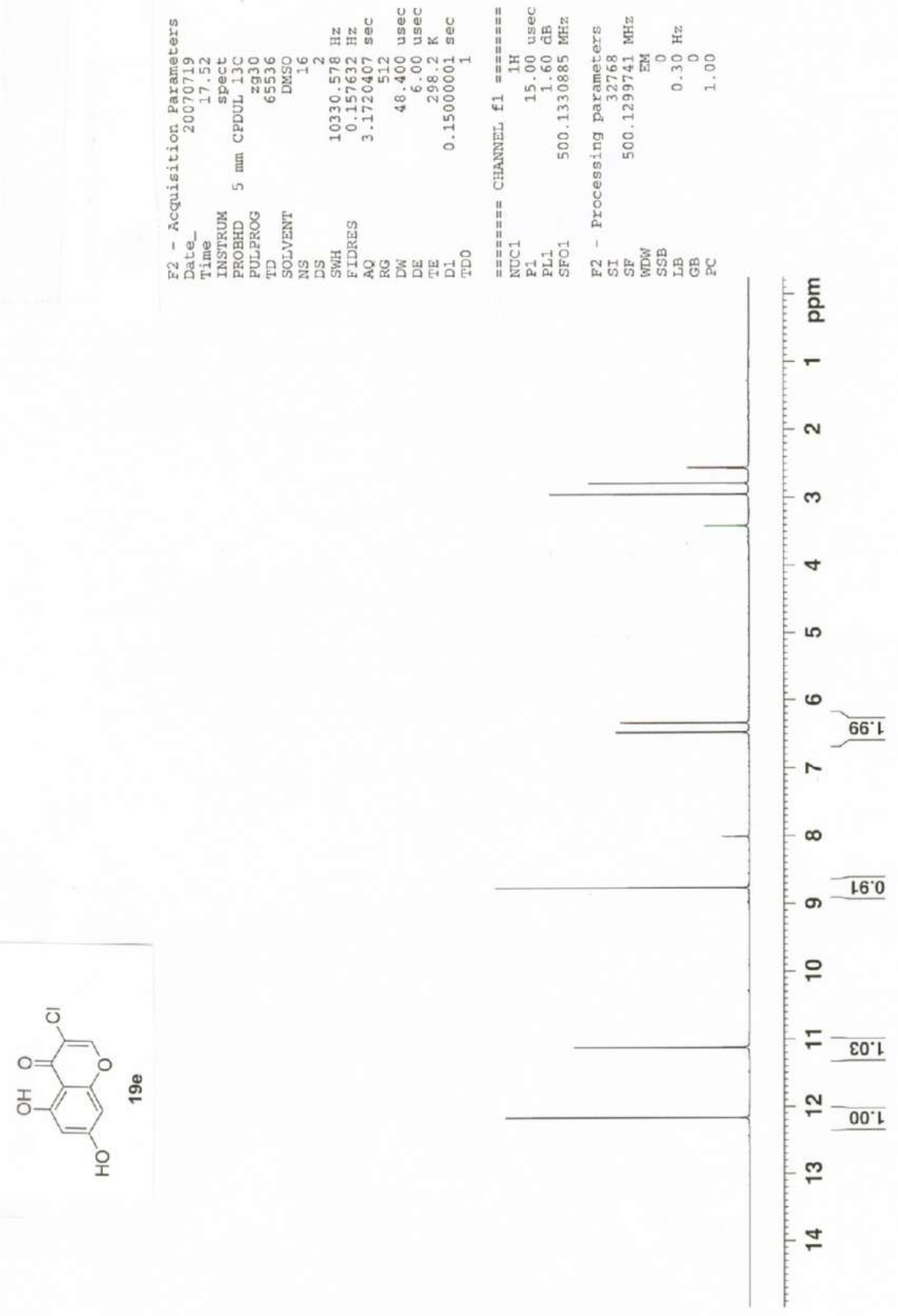


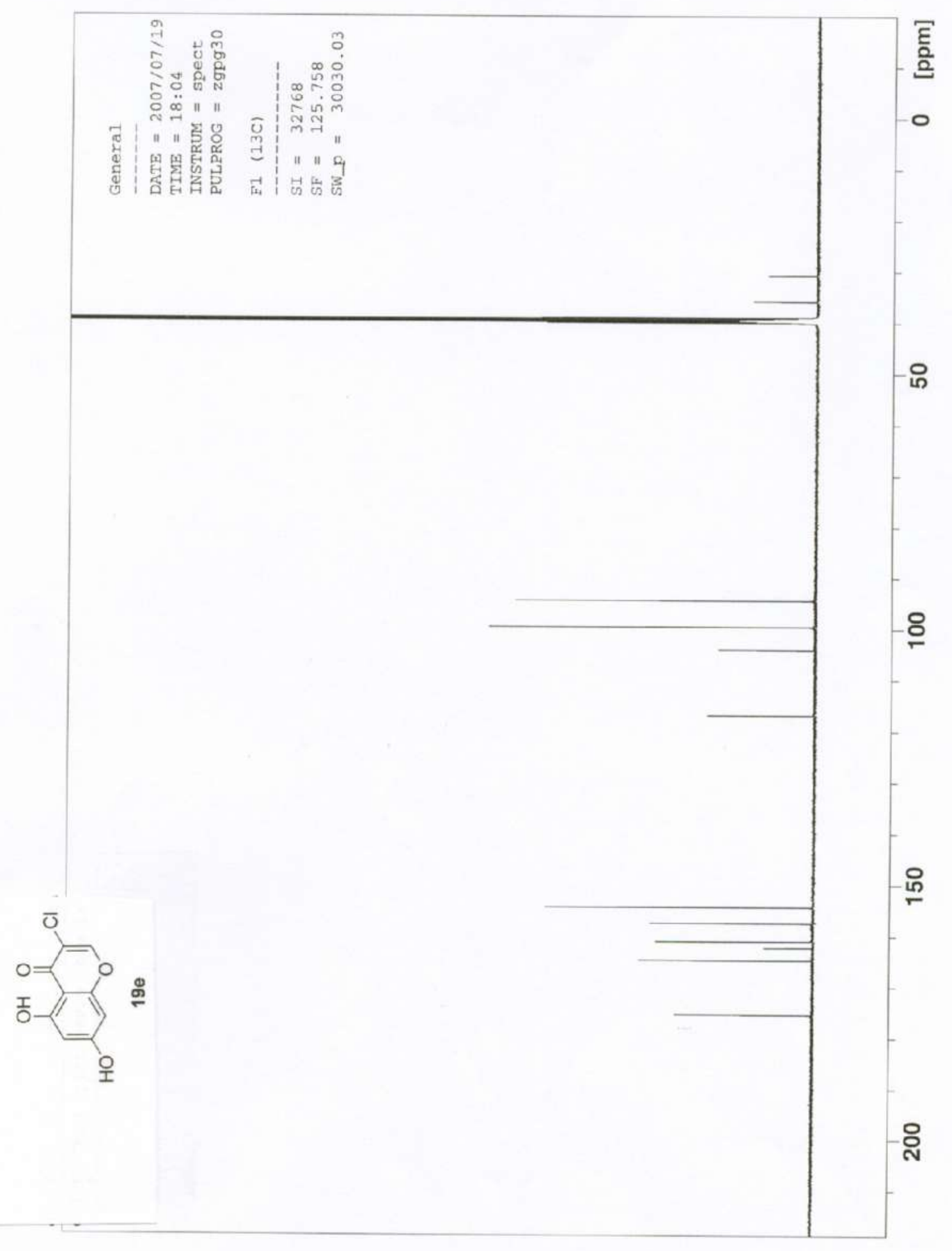



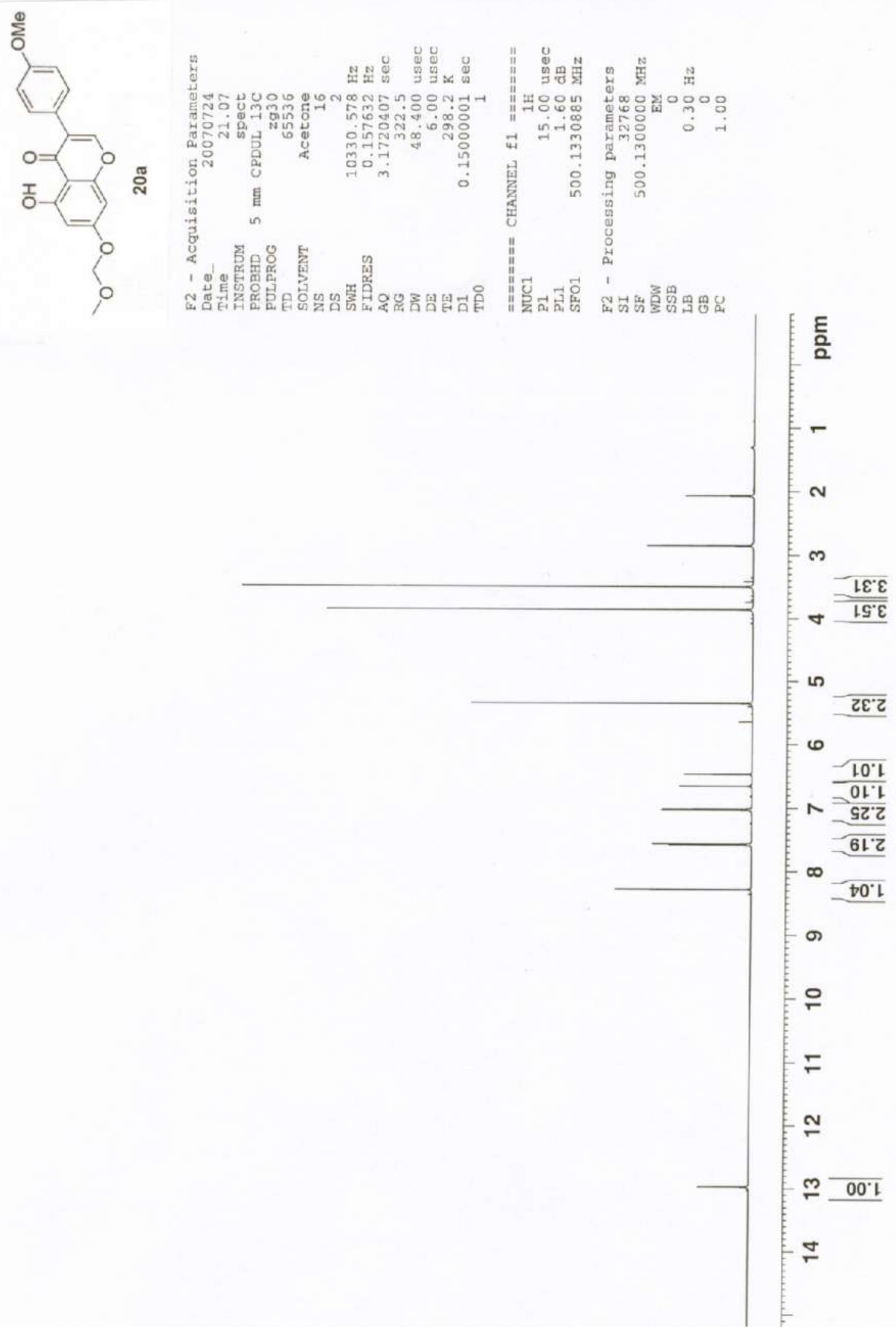


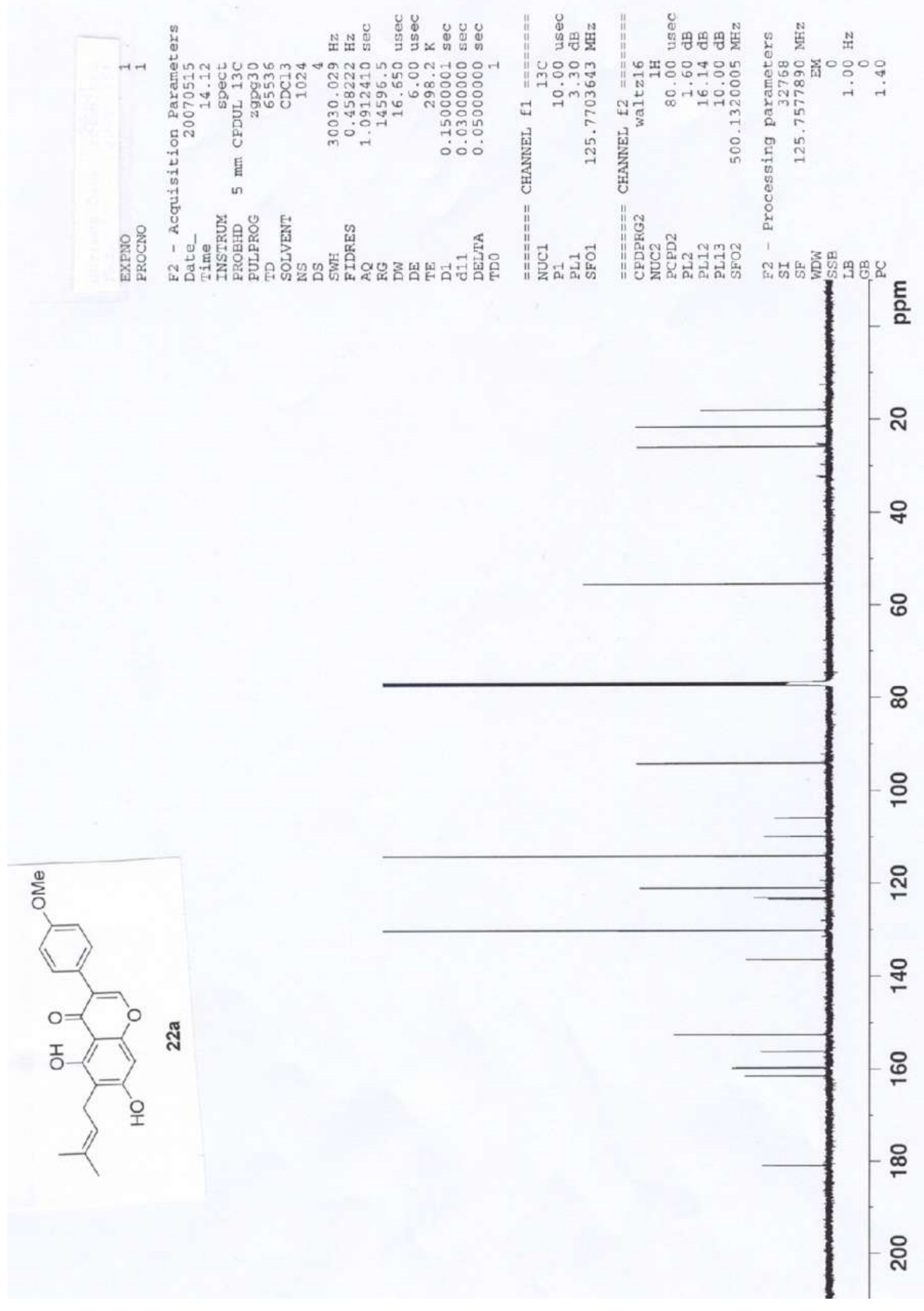




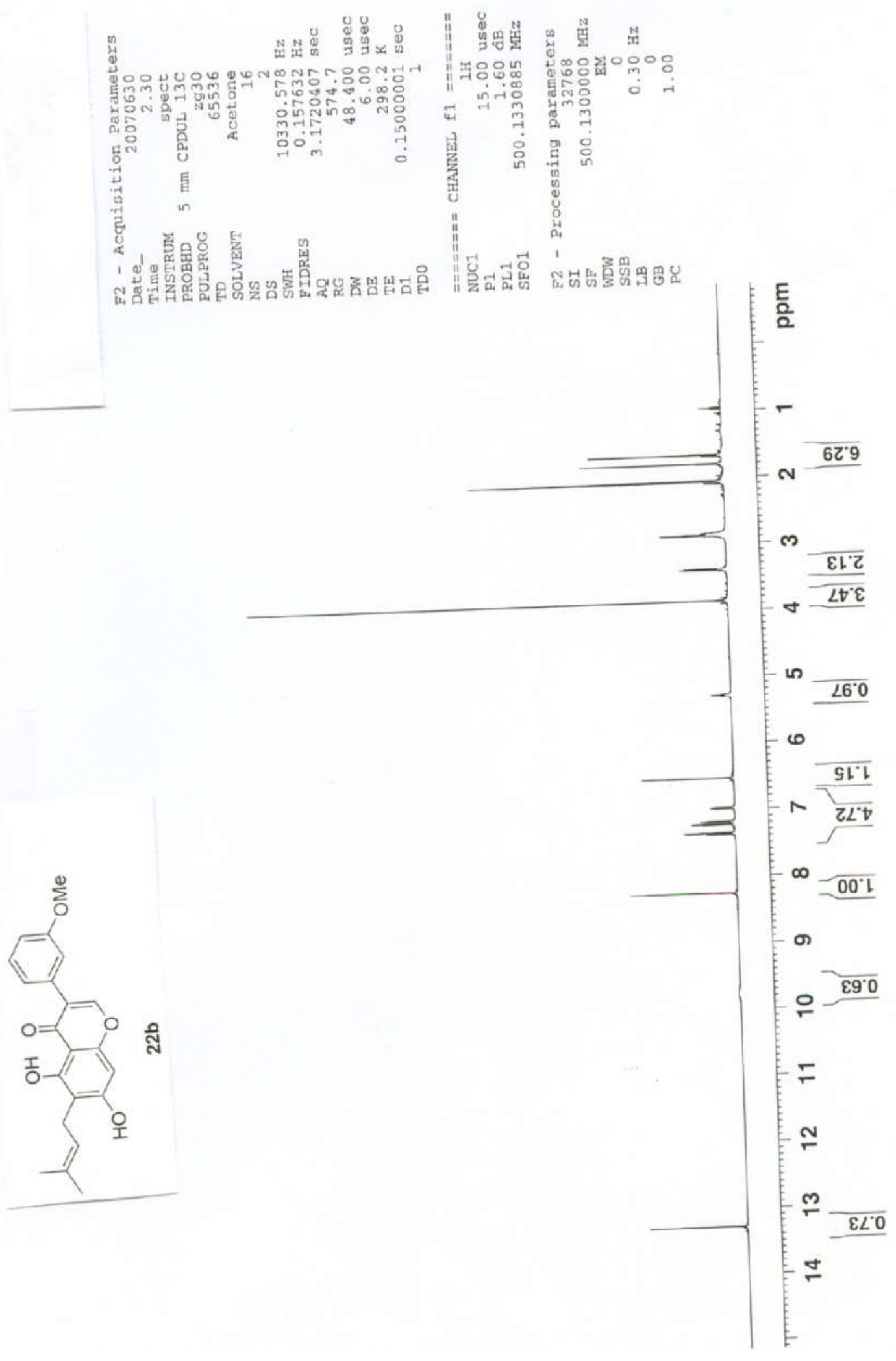




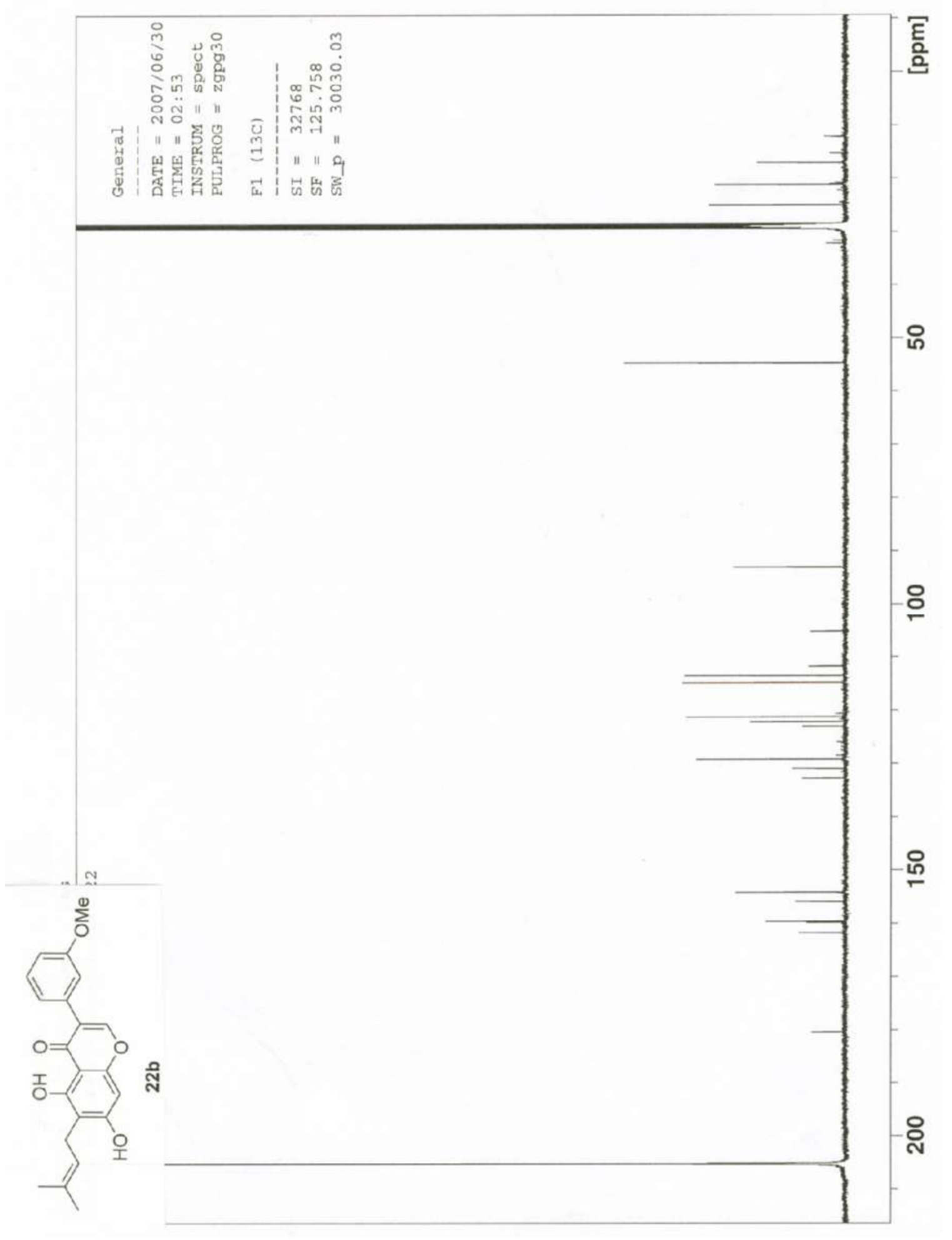



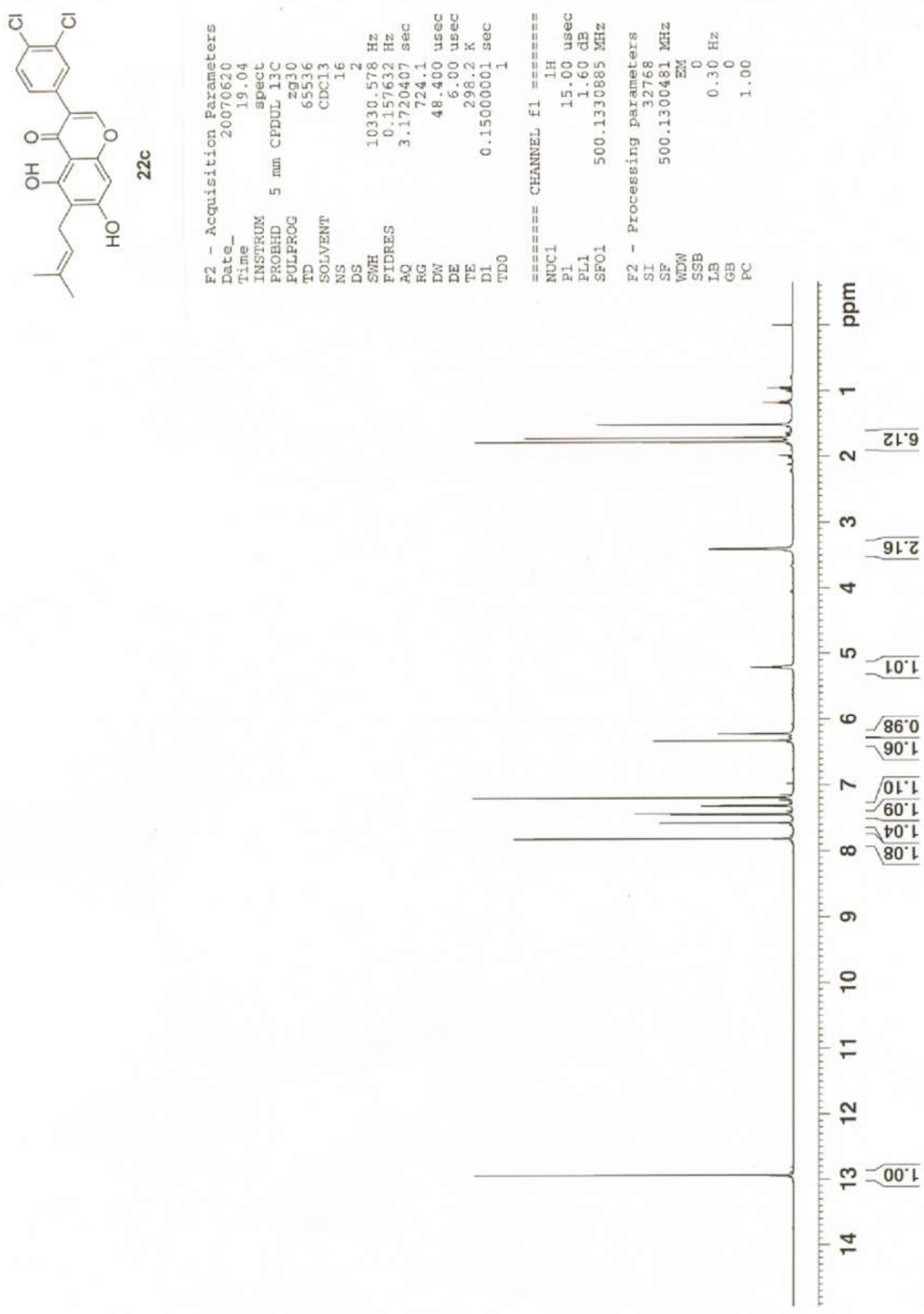

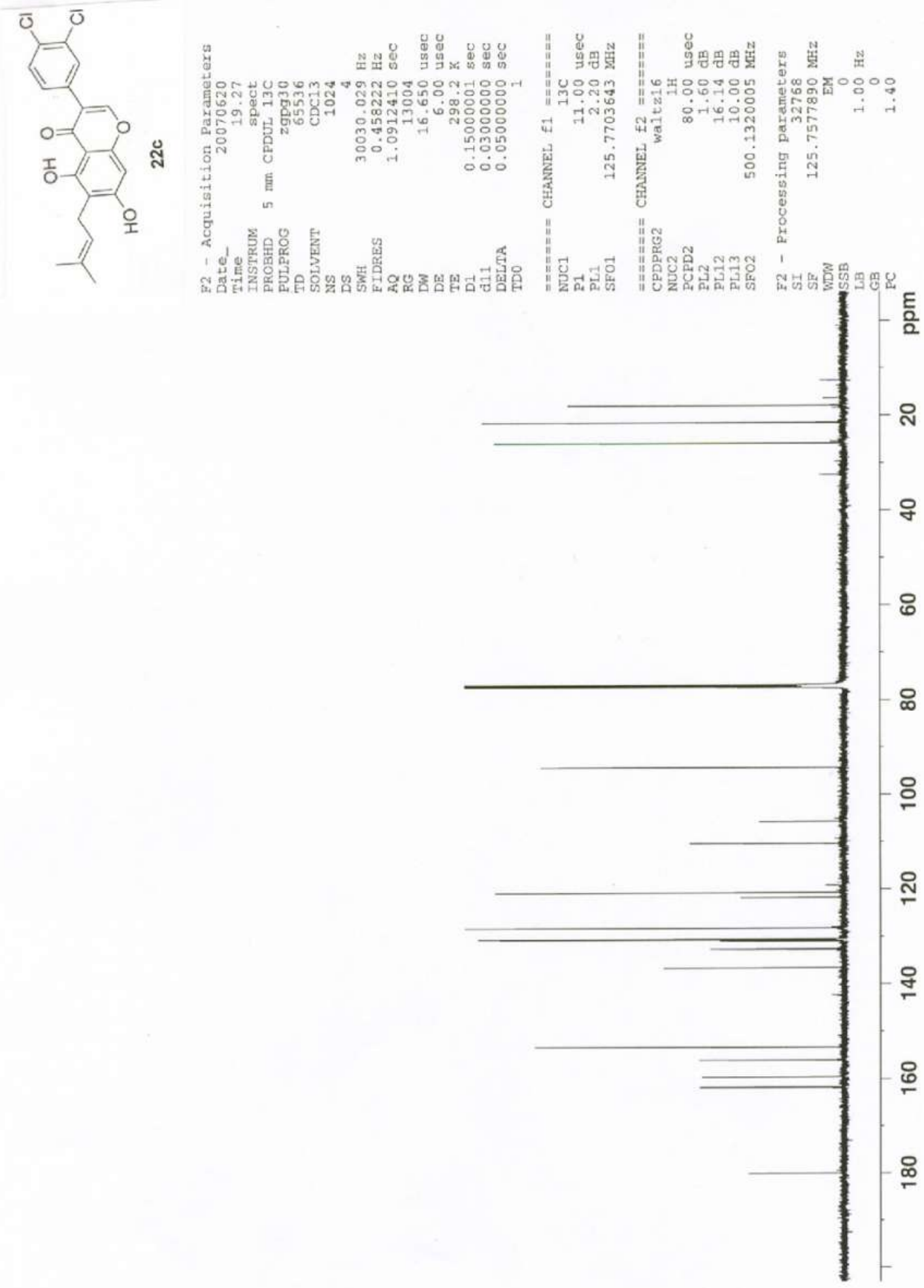


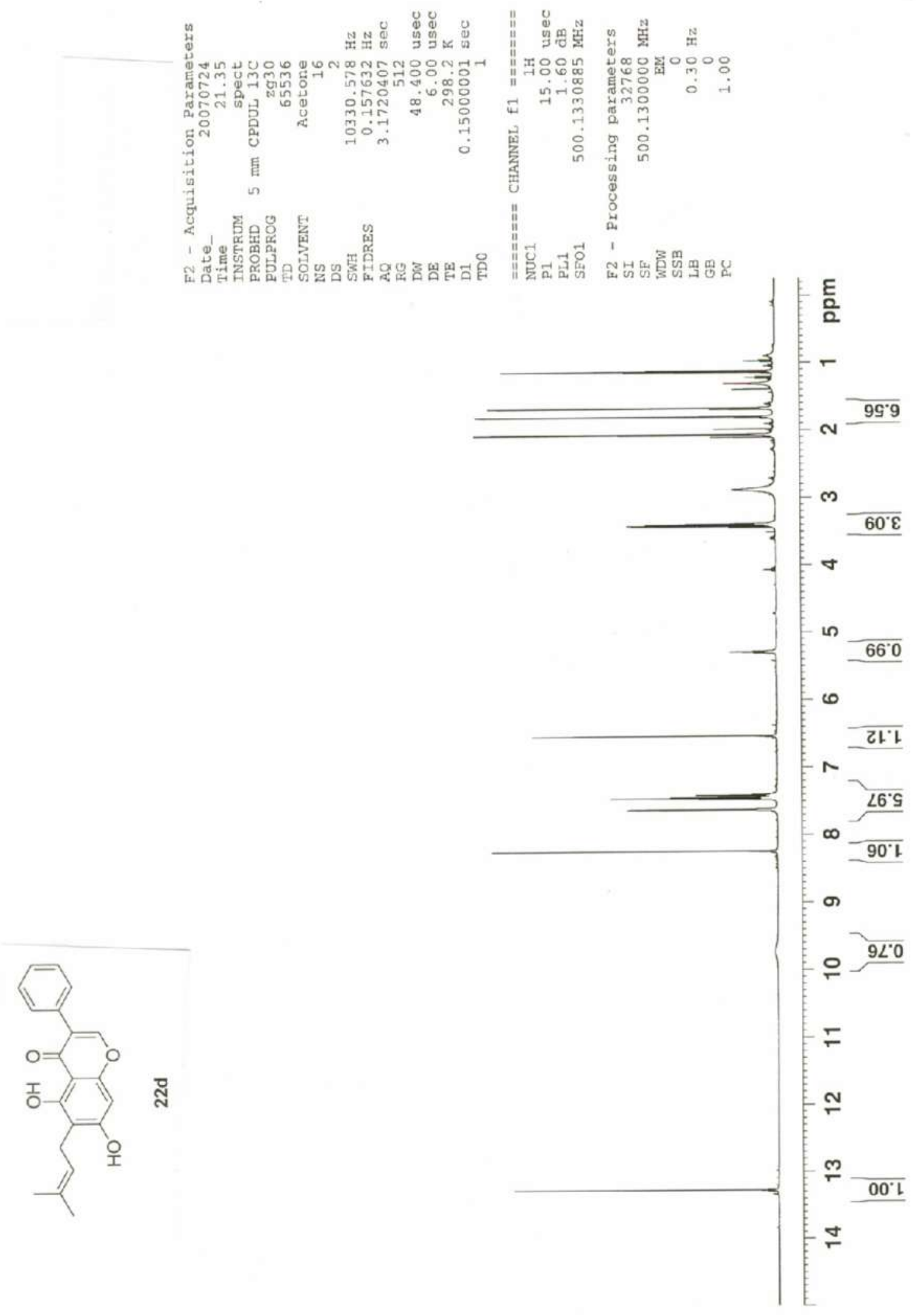




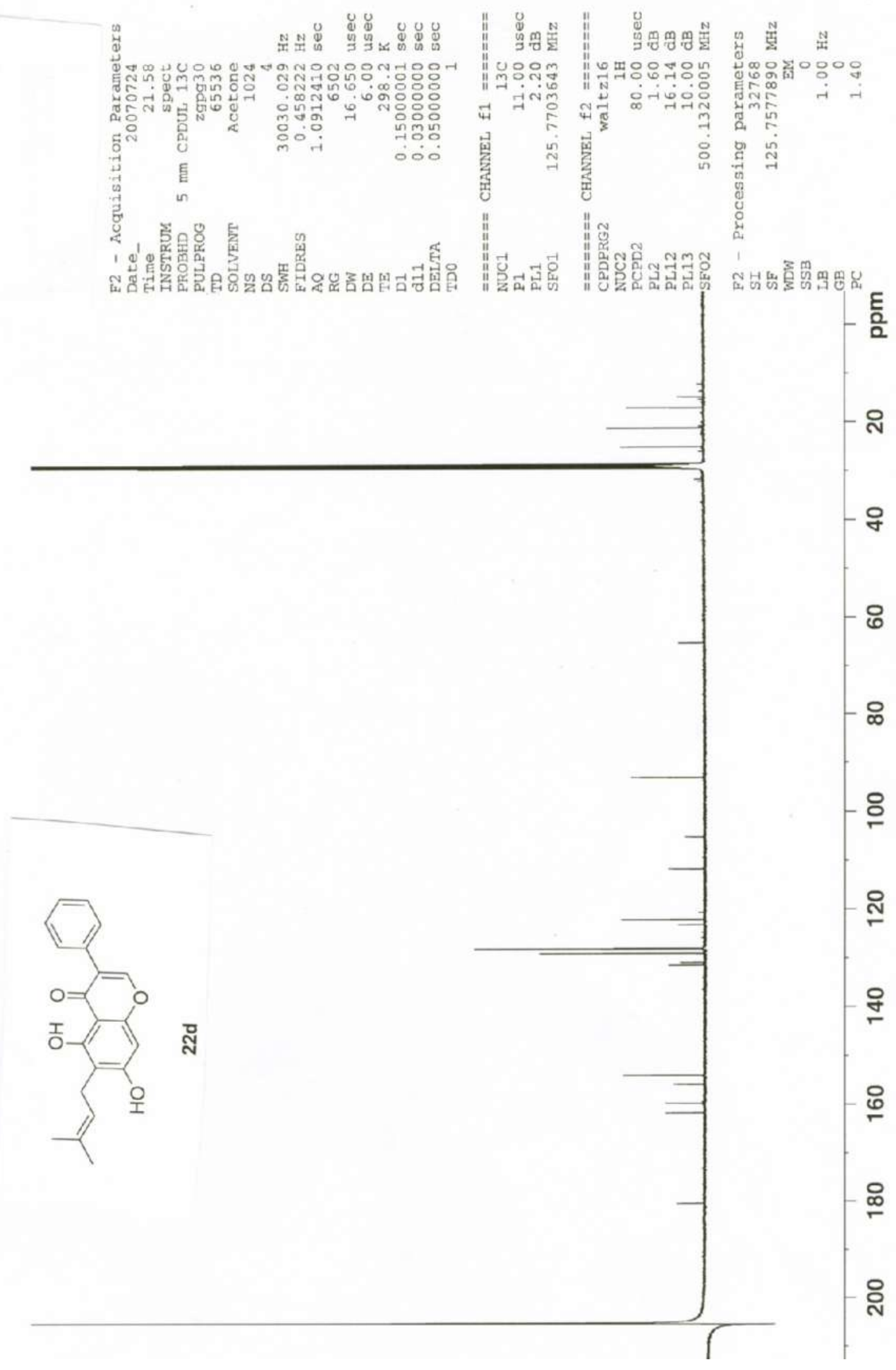




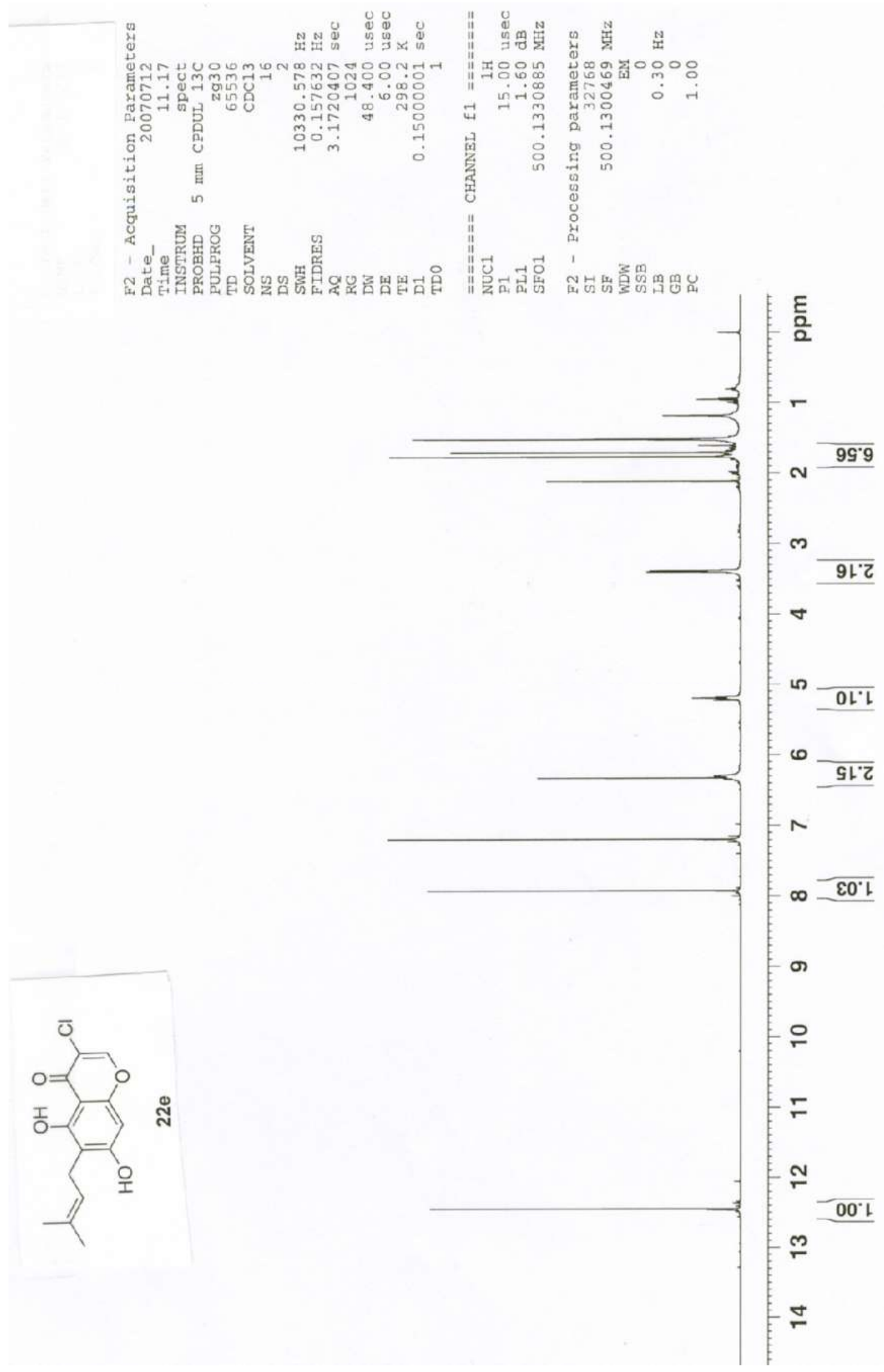




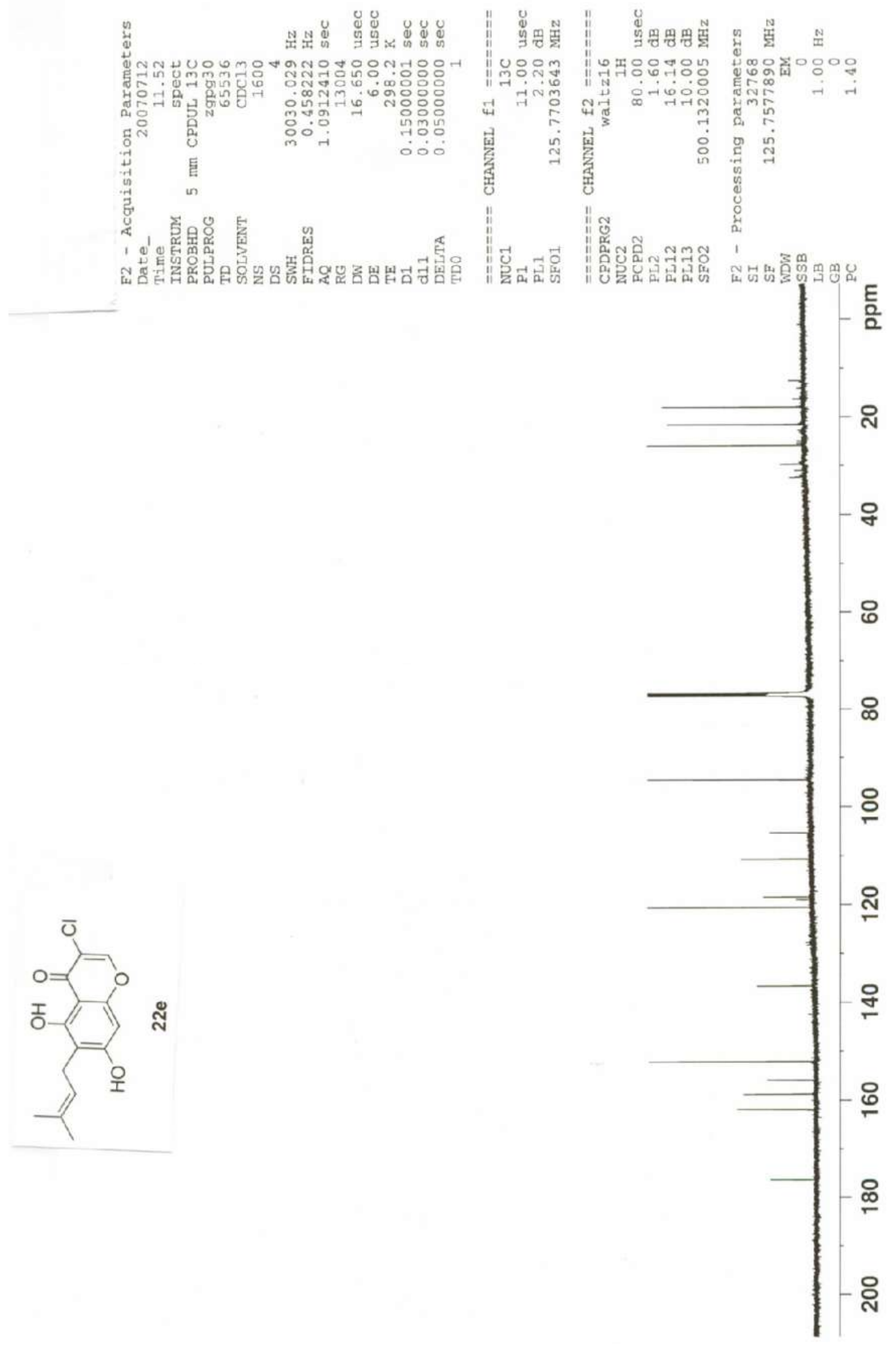




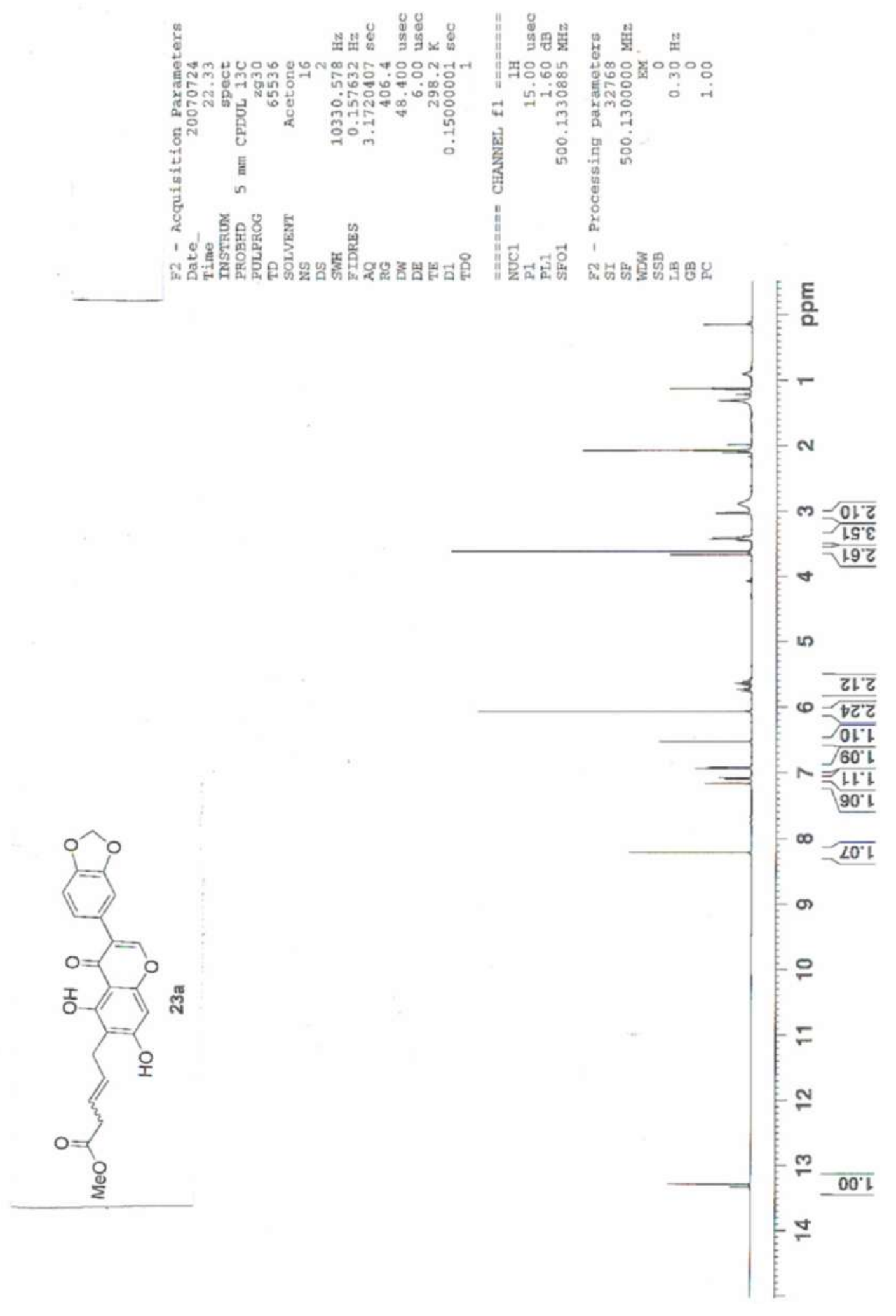




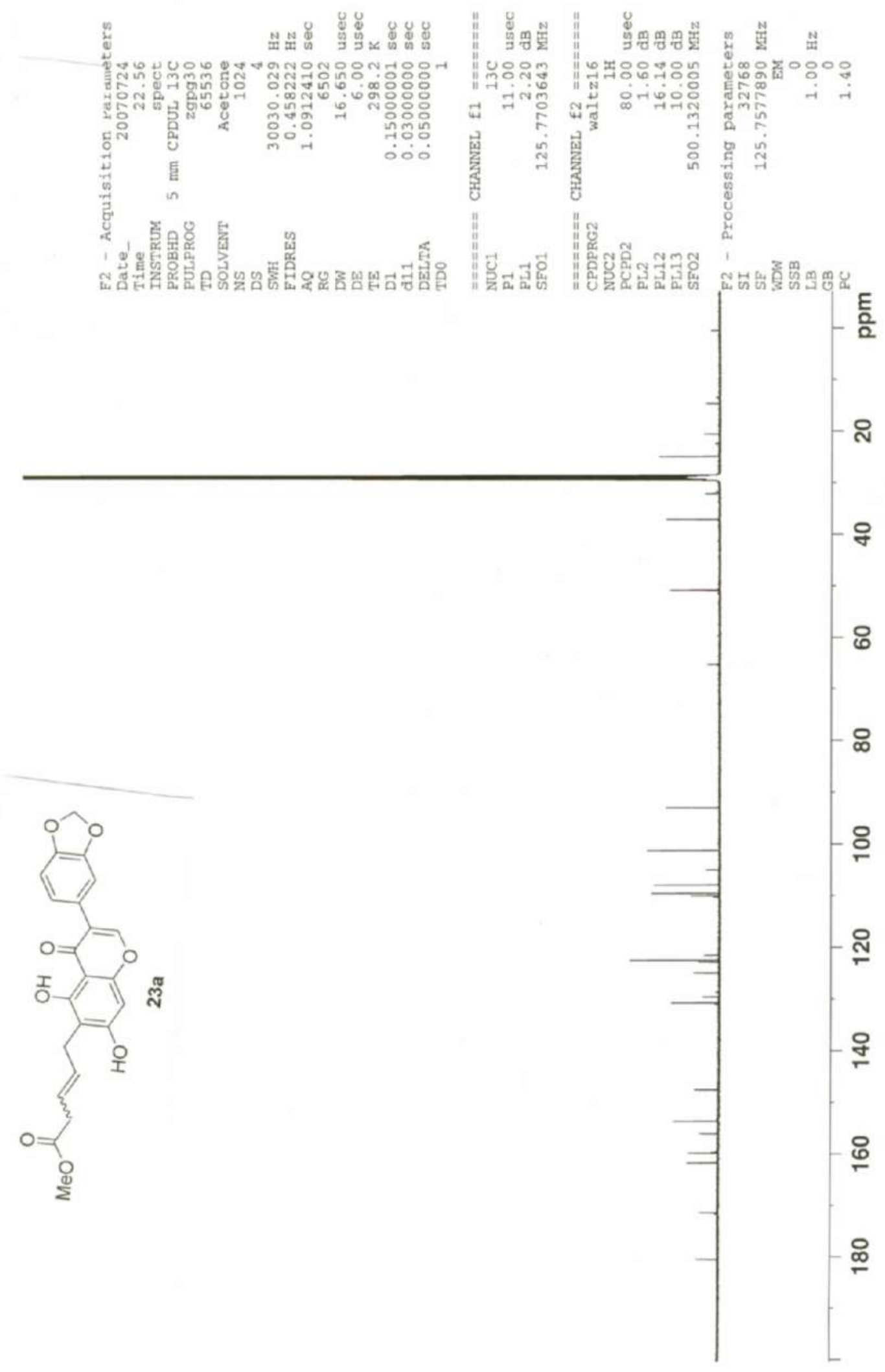




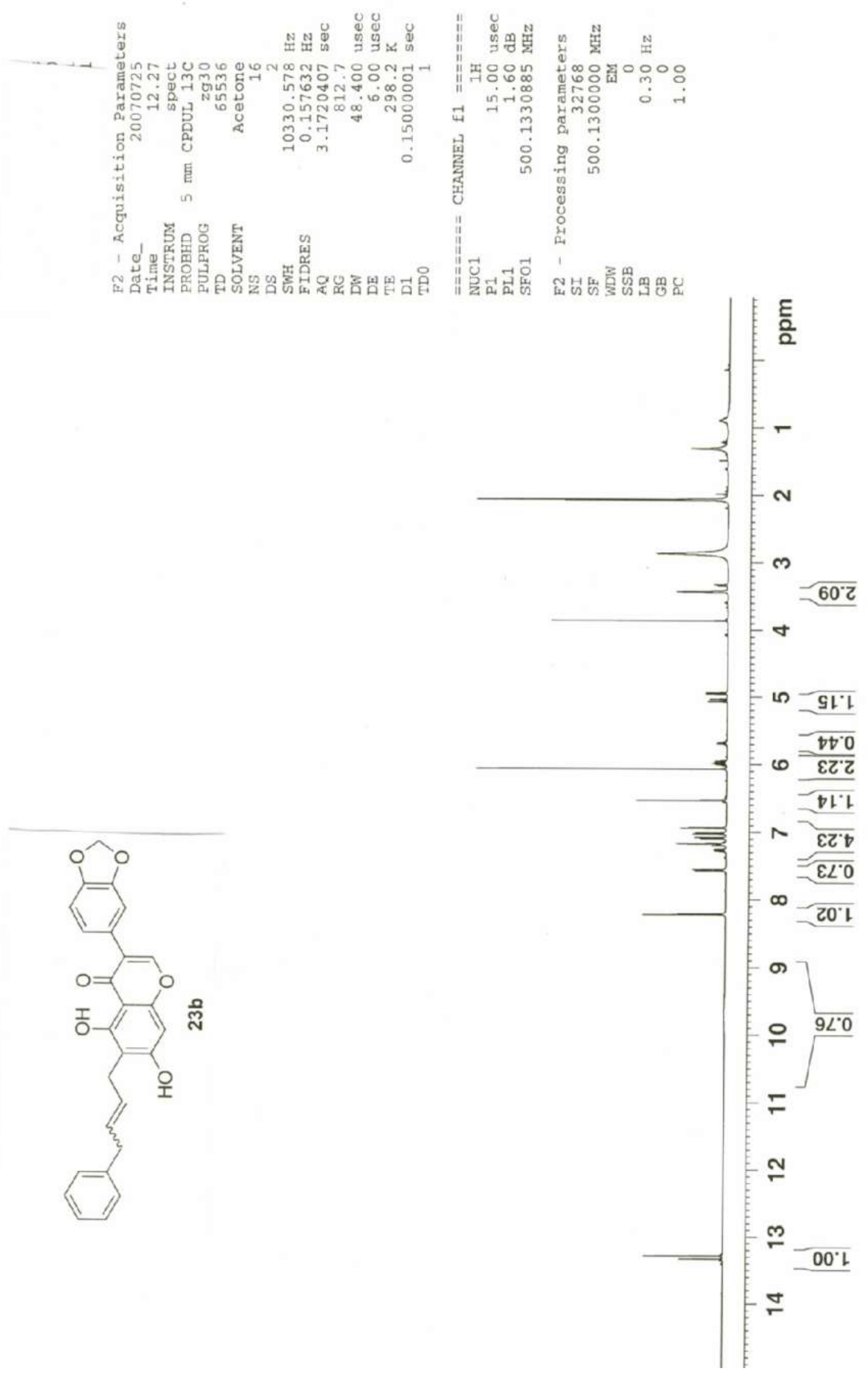




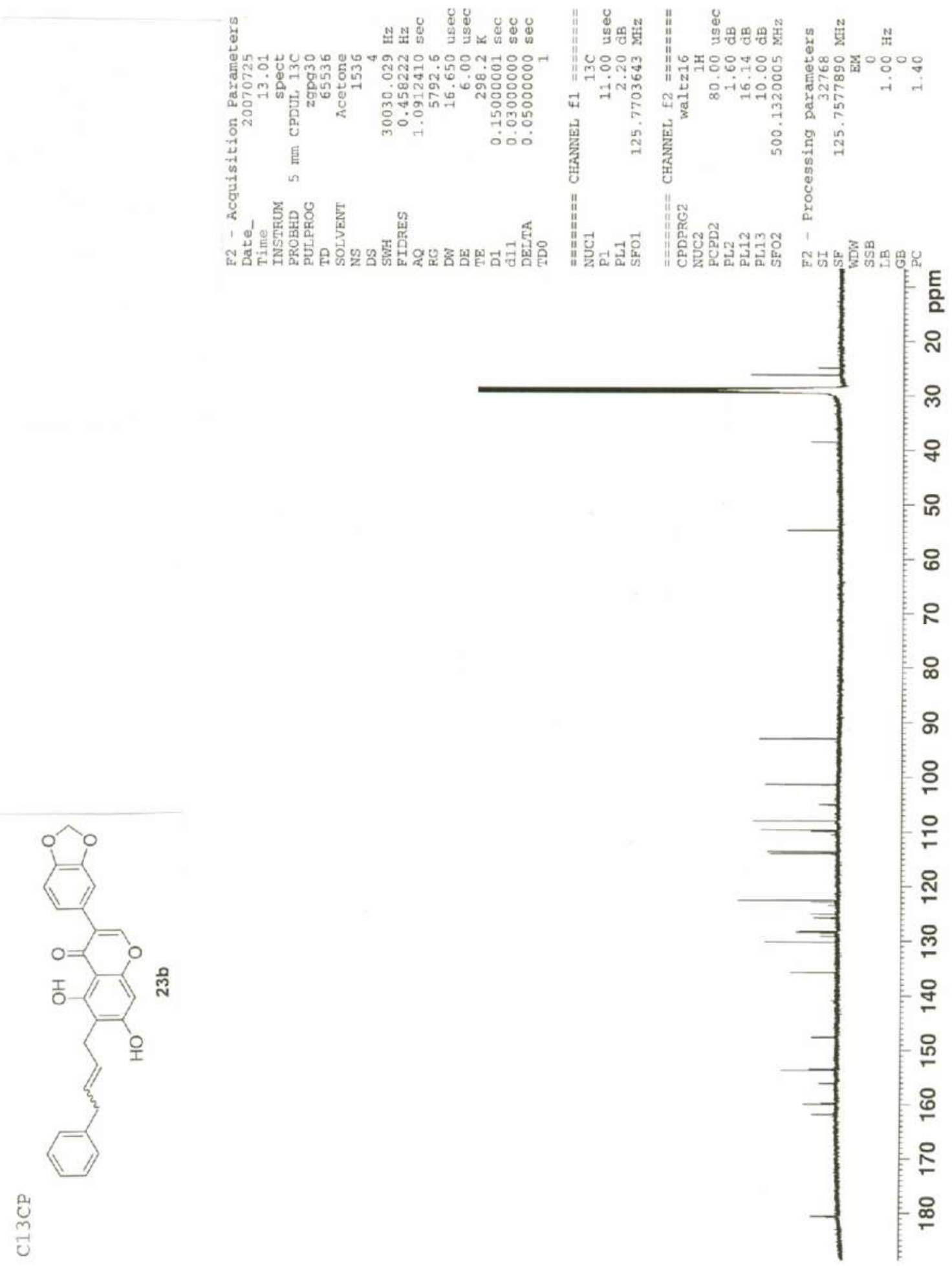

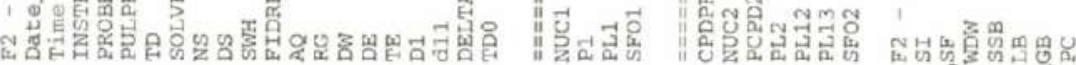

